\title{
THE EFFECT OF ${ }^{60}$ Co IRRADIATION ON PASSIVATED AND NONPASSIVATED \\ AVALANCHE DIODES \\ BIASED NEAR BREAKDOWN
}

DECEMBER 1968

\section{AEC RESEARCH \& DEVELOPMENT REPORT}




\section{LEGAL NOTICE}

This report was prepared as an account of Government sponsored work. Neither the United States, nor the Commission, nor any person acting on behalf of the Commission:

A. Makes any warranty or representotion, expressed or implied, with respect to the accuracy, completeness, or usefulness of the information contained in this report, or that the use of any information, apparatus, method, or process disclased in this report may not infringe privately owned rights; or

B. Assumes any liabilities with respect to the use of, or for damages resulting from the use of any information, apparatus, method, or process disclosed in this report.

As used in the above, "person acting on behalf of the Commission" includes any employee or contractor of the Commission, or employee of such contractor, to the extent that such emplayee or contractor of the Commission, or employee of such contractor prepares, disseminates, or provides access to, any information pursuant to his employment or contract with the Commission, or his employment with such contractor.

\section{PACIFIC NORTHWEST LABORATORY}

RICHLAND, WASHINGTON

operated by

BATTELLE MEMORIAL INSTITUTE

for the

UNITED STATES ATOMIC ENERGY COMMISSION UNDER CONTRACT AT(45-1)-1830 
BNWL -788

$\mathrm{UC}-37$, Instruments

\author{
THE EFFECT OF ${ }^{60}$ Co IRRADIATION \\ ON PASSIVATED AND NONPASSIVATED \\ AVALANCHE DIODES \\ BIASED NEAR BREAKDOWN
}

By

N. C. Hoitink

Control and Instrumentation Department

Systems and Electronics Division

December 1968

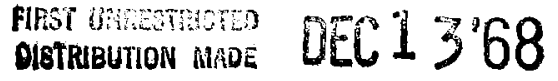

BATTELLE MEMORIAL INSTITUTE

PACIFIC NORTHWEST LABORATORY

RICHLAND, WASHINGTON 99352 
Printed in the United States of America Available from

Clearinghouse for Federal Scientific and Technical Information National Bureau of Standards, U.S. Department of Commerce Springfield, Virginia 22151

Price: Printed Copy $\$ 3.00$; Microfiche $\$ 0.65$ 


\author{
THE EFFECT OF ${ }^{60}$ CO IRRADIATION \\ ON PASSIVATED AND NONPASSIVATED \\ AVALANCHE DIODES \\ BIASED NEAR BREAKDOWN \\ N. C. Hoitink
}

\begin{abstract}
Irradiation of the same type of passivated and nonpassivated avalanche diodes was observed to produce significantly different effects. Irradiation in a $2 \times 10^{6} \mathrm{R} / \mathrm{hr},{ }^{60}$ Co gamma field, with the diodes biased at $5 \%$ below breakdown permitted investigation of the effects on multiplication mode operation, a mode passibly suitable for application of diodes as radiation detectors. During the experiments, encapsulated diodes and those with the container removed but with vacuum applied received exposures up to $1.4 \times 10^{8} \mathrm{R}$. Comparison of performance in the gamma field indicated passivated diodes to possess superior operational characteristics, particularly for stability and predictability of the reverse current, both with and without encapsulation. The nonpassivated devices evidenced continuous changes in reverse current, especially with the encapsulation removed. Operational recovery of passivated diodes with bias applied occurred quickly following physical removal from the gamma field. Similar recovery for the nonpassivated diodes required removal of the bias voltage. Analysis of the experimental results indicated that surface effects contributed substantially to the major changes in characteristics of the diodes.
\end{abstract}




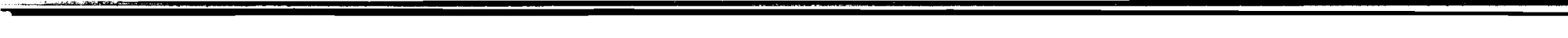

$\checkmark$ 


\section{TABLE OF CONTENTS}

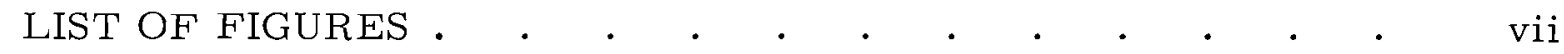

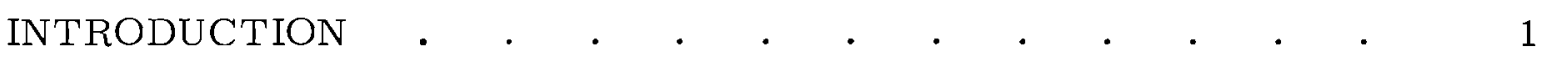

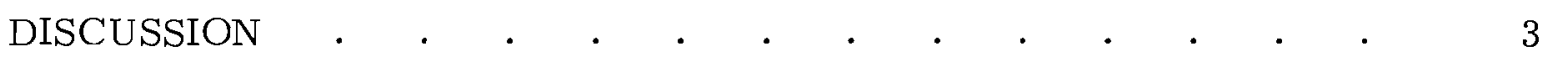

THEORY . . . . . . . . . . . . . . . . . . 6

p-n Junction Reverse Bias Characteristics . . . . . . . 6

Diode Avalanche Breakdown . . . . . . . . . 13

Effects of Radiation on $\mathrm{p}-\mathrm{n}$ Junctions $\quad . \quad$. $\quad . \quad$. $\quad . \quad$. 18

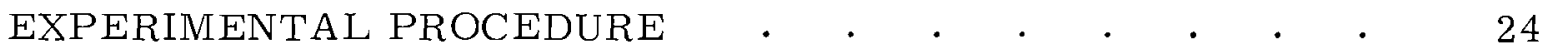

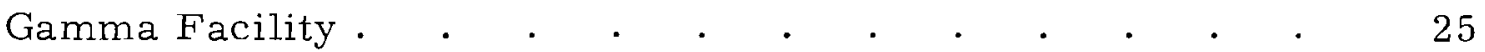

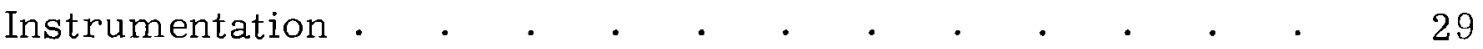

Measurement Procedure $\quad . \quad$ •

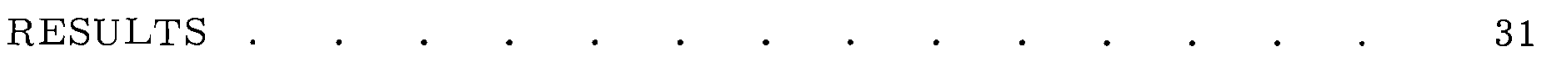

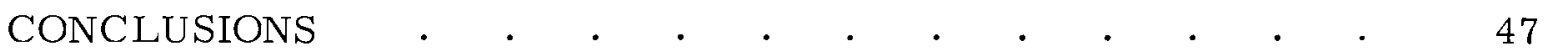

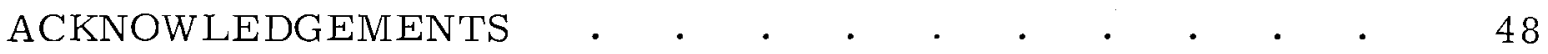

REFERENCES •

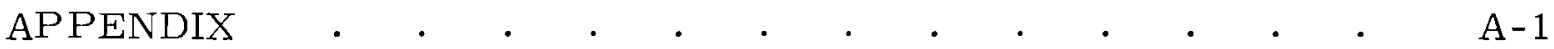

DISTRIBUTION $\quad . \quad$. . . . . . . . . . . . Distr-1 


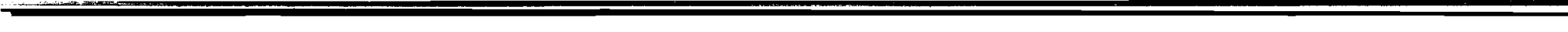

$\checkmark$ 


\section{LIST OF FIGURES}

1 Diagram of Important Regions in $\mathrm{p}^{+} \mathrm{n}$ Diode 8

2 Effect of Surface Charge on a $\mathrm{p}_{\mathrm{n}}^{+}$Junction $\quad 12$

3 Typical Reverse V-I Characteristic Showing the Effect of Multiplication

4 Multiplication as a Function of Normalized Bias Voltage for Various $n$

5 Gamma Facility 26

$6 \quad$ Diode Test Holder Assembly 27

7 Gamma Flux Profiles 28

8 Test Instrumentation $\quad 30$

9 Typical Reverse Current Recordings for $\mathrm{V}_{\text {Bias }}=0.95$ VBD.

10 Consecutive V-I Plots Showing Effects of Dropping to Zero Bias Volts

11 Preirradiation V-I - Diode Number $17 \quad 43$

12 Normal Irradiation V-I Curve - Diode Number 17

13 Premature Breakdown or Microplasma - Diode Number $17 \quad 45$

14 V-I Curve After Irradiation - Diode Number $17 \quad 46$ 


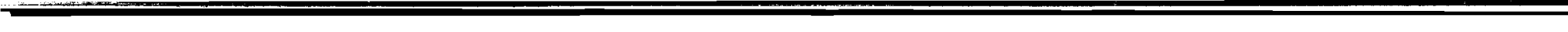

$\checkmark$ 


\author{
THE EFFECT OF ${ }^{60}$ CO IRRADIATION \\ ON PASSIVATED AND NONPASSIVATED \\ AVALANCHE DIODES \\ BIASED NEAR BREAKDOWN \\ N. C. Hoitink \\ INTRODUCTION
}

Numerous studies have focused on the radiation effects of semiconductor devices, both transistors and diodes, in many different kinds of radiation fields. However, published information detailing such experiments for avalanche diodes operating in or near breakdown, an area of considerable interest to engineers and scientists, has been scarce. Recent work with solid state radiation detectors has resulted in a new detection technique in which the multiplication characteristics of avalanche diodes biased within a few percent of breakdown produce a charge multiplication within the detector. This effect significantly improves the sensitivity and the signal to noise ratio available in such detectors.

The primary effect of irradiation by ${ }^{60} \mathrm{Co}$, which emits two photons or gamma rays of $1.17 \mathrm{MeV}$ and $1.33 \mathrm{MeV}$ in energy with each disintegration, centers on the formation of electron-hole pairs in the detection devices. This effect, in the absence of permanent damage to the crystal structure appears to be transitory. Such transient effects disappear after removal of the device from exposure to the ionizing radiation. Permanent effects generally result from defects in the crystal produced by interaction with more destructive types of radiation typified by high energy particles. Although the production of crystal lattice defects associated with permanent radiation effects is usually not considered for gamma irradiation, some crystal structure damage does occur. Thus, measurable permanent effects, depending upon the total exposure (absorbed energy), the doping concentrations of the silicon, and the energy of the incident gamma rays, may result. (1) Some effects may last for hours or days after removal of 
the device from the radiation source. Thus, while these effects seem to fit between the permanent and the transient definitions, historic treatment considers them and such mechanisms as radiation-induced atom displacements demonstrating short annealing times to be transitory.

In addition to the described effects, radiation-induced changes in semiconductors may manifest themselves in bulk properties variations, at or near the surfaces, or in the encapsulation gas surrounding the device. Many published reports have ignored one or more of these possible locations, occasionally with sufficient justification. However, generally inclusive investigations demand full consideration of such effects.

Surface and environmental conditions have rather important and significant effects on devices operating in or near breakdown. Garrett and Brattain ${ }^{(2)}$ demonstrated that surface breakdown generally, occurs before body breakdown and that conditions for surface breakdown appear to be affected significantly by surface charge density, surface preparation, and ambient conditions. Mitchell ${ }^{(3)}$ notes the importance of radiation surface effects with the conclusion that these mask bulk effects in modern diffused devices. He further concludes that effects noted on nonpassivated devices appear to be many and varied and may be traced to charge buildup on the surface of the device due to ionization of the encapsulation gas caused by the radiation field. Manufacturers of devices designed to be operated in or near avalanche seem well aware of surface effects and have taken steps to reduce the surface characteristics effect on device operation. Because of the need to desensitize avalanche devices to surface conditions, the resulting avalanche devices may, by virtue of design, be less susceptible to radiation-induced surface effects than are normal diodes and transistors. 
One particular surface treatment important in modern silicon devices centers on application of a thin layer of $\mathrm{SiO}_{2}$ ("passivation") over the surface of the diode or transistor. This treatment, while effectively isolating the surface from ambient conditions, does not necessarily eliminate all surface effects and may result in some other surface effect characteristics, as described by Snow.

In view of the radiation effects on semiconductor devices described by other experimenters, the investigations reported herein were centered on the ${ }^{60}$ Co irradiation effect on avalanche diodes biased to within $5 \%$ of breakdown.

The experiments utilized twenty Motorola 1 N2846 $200 \mathrm{~V}$, $50 \mathrm{~W}$, Zener diodes, where 10 were of the passivated variety. Thus, the obtained data describe the effects of passivation on the radiationinduced surface effects of this particular diode. Experiments also focused on both diode types with the encapsulation removed and with a modest vacuum applied to the test assembly. These experiments provide information regarding ambient conditions related to radiation effects, both for the passivated and nonpassivated devices. Selection of the 1 N2846 diodes was on observations made by A. R. Jones $(5)$ in which he indicated the suitability of such diodes for radiation detection.

\section{DISCUSSION}

For a number of years, semiconductor diodes have been applied beneficially, both experimentally and routinely, to the detection of radiation. Applications have included detection of all types of radiation, both particle and electromagnetic, the latter including gamma rays, X-rays, laser emissions, and light. Although both silicon and germanium diode detectors demonstrate usefulness, their applications are somewhat different. Silicon detectors evidence ease of use because of their inherently lower leakage currents at room temperature. However, silicon diodes require more energy for generation 
of an electron-hole pair than do the germanium units. For this reason, germanium detectors are beneficially applied to low energy detection problems wherein typical operation at liquid nitrogen temperatures reduces diode leakage and noise to acceptable levels.

Recently Huth ${ }^{(6)}$ of the General Electric Space Science Laboratory developed the charge multiplying contoured diode detector, in effect, an avalanche diode biased very near breakdown in the charge multiplication region of operation. Charge multiplication near breakdown, not a new discovery, has been investigated by many in past years. $(2,7-10)$ Huth apparently first applied the effect to radiation detection methods and, in the process of his investigations, developed a high voltage avalanche detector with some characteristics similar to those common in multiplier phototubes. Because these detectors operate in the neighborhood of $2 \mathrm{kV}$, some care in device design is required. In order to achieve this high breakdown voltage, control of surface conditions becomes mandatory to alleviate breakdown. For this reason, Huth beveled the surface of the diode in a manner to achieve the desired characteristics. This beveling led to the name "surface contoured" diodes. Others also use this technique in device fabrication to control surface breakdown.

The high voltage avalanche diode detectors provide gains of about 1000 when operated within a few volts of breakdown, thus creating a detector capable of greatly enhancing the signal to noise ratio of the detection process. This ratio gain permits low energy measurements of less than $1 \mathrm{keV}$ for gamma photons, for example, at room temperature. The multiplication process will be described in more detail later during consideration of the theory of avalanche breakdown in $\mathrm{p}-\mathrm{n}$ junctions. At this point, the process can be considered analogous to multiplication in a gas device. A region of high electric field intensity exists within the depletion region of a reverse biased $\mathrm{p}-\mathrm{n}$ junction. Following generation of an electron-hole pair within this depletion region, by a gamma or $X$-ray for instance, the electron and hole are swept through the depletion 
region towards the positive and negative edges of the depletion region producing additional electron-hole pairs by ionization if an adequate electric field exists. The multiplication factor equates, then, to the total number of electron-hole pairs collected per electron-hole pair generated initially.

Since the operating voltage (bias) of charge multiplying diodes needs to be within a few percent of breakdown and since multiplication demonstrates strong sensitivity to bias voltage changes near breakdown, the characteristics changes resulting from various conditions of operation must be known. Because one particular environment for application of these detectors is in high level gamma and X-ray radiation fields, the breakdown voltage and bias current under such conditions must be considered. Of course, the most desirable situation would be for the breakdown voltage to remain constant and for the current to be a function of exposure rate. As little information appears to be available regarding radiation effects on $\mathrm{p}-\mathrm{n}$ junctions operating in or near breakdown, this subject will be investigated more fully in a later discussion of radiation effects.

As indicated previously, the avalanche multiplication phenomenon exists in most avalanche diodes. The contoured diode typifies the few devices manufactured specifically to take advantage of the multiplication phenomenon for some useful purpose. However, generally obtainable avalanche diodes should be useful in the same mode of operation with certain qualifications. In this regard, A. R. Jones of Canada's Chalk River Laboratory has reported ${ }^{(11)}$ the possibility of using specific low leakage, high power, high voltage commercial diodes for detection applications requiring charge multiplication. One diode suggested by Jones and thus utilized in the experiments described in this report is the Motorola $1 \mathrm{~N} 2846,200 \mathrm{~V}, 50 \mathrm{~W}$, Zener device. This unit demonstrates an average maximum multiplication of about 12, much lower than that achieved with the contoured diodes 
but quite useful for specific situations. Thus, another useful application of the avalanche diode would be as a substitute for the contoured diode in radiation effects studies. One limitation to this application requires consideration of diode doping levels, which are much higher in the lower voltage avalanche diode. This has significant importance in radiation effects.

Recent work by Huth and others indicates the considerable effort being applied to producing lower voltage charge multiplying diode detectors with high gain in an attempt to decrease the problems associated with the higher voltage devices and circuits. Success of this work should achieve doping concentrations closer to those in the commercial avalanche diodes used in the experiment described in this report.

The availability of the commercial diode (as opposed to the scarcity of the experimental surface-contoured diodes) coupled with the information to be learned about radiation effects on low voltage diodes biased near breakdown provided the impetus to conduct these radiation effects studies.

\section{THEORY}

p-n JUNCTION REVERSE BIAS CHARACTERISTICS

Important considerations regarding reverse biased $\mathrm{p}-\mathrm{n}$ junctions require explanation and development to achieve a better understanding of the variables of interest in radiation effects studies. Conditions near breakdown, of primary importance in this report, require particular attention.

The following equation describes the ideal diode:

$$
I \quad=I_{S}(\exp q V / k T-1)
$$

where

$\mathrm{I}=$ Diode current, under either forward or reverse bias

$I_{S}=$ Bulk diffusion saturation current

$\mathrm{q}=$ Electron charge $\left(1.6 \times 10^{-19}\right.$ coulomb) 
$\mathrm{V}=$ Voltage across junction, $\mathrm{V}>0$ for forward bias

$\mathrm{k}=$ Boltzmann Constant $\left(1.38 \times 10^{-23} \mathrm{~J} /{ }^{\circ} \mathrm{K}\right)$

$\mathrm{T}=$ Absolute temperature in $\% \mathrm{~K}$

$\frac{\mathrm{kT}}{\mathrm{q}}=0.026 \mathrm{~V}$ at room temperature $\left(\mathrm{T}=300^{\circ} \mathrm{K}\right.$

Thus, for a reverse bias voltage, $-\mathrm{V}$, much larger than $\mathrm{kT} / \mathrm{q}$, the expression approaches a constant, $I_{S}$. However, the theory needs further consideration to explain the true reverse current situation. The following discussion elaborates on this point, where the imposed condition will be that $|-\mathrm{V}|>>\mathrm{kT} / \mathrm{q}$, a consideration sufficiently fulfilled at reverse bias voltage greater than approximately $1 \mathrm{~V}$.

Figure 1 illustrates the important regions of a $\mathrm{p}-\mathrm{n}$ junction used in the description of the voltage and current condition during reverse bias. For equilibrium consideration, electron-hole pairs are generated throughout the semiconductor. Under zero applied voltage, however, all the electrons and holes recombine and no current flow occurs. For reverse bias, the electrons and holes move away from each other, thereby reducing the probability of recombining and producing a net current flow as a result of the difference between rates of generation and recombination of the electron-hole pairs. Generation of electron-hole pairs in various regions of the semiconductor results in different components of the total reverse current, with varying degrees of importance depending upon the material of the semiconductor. Current due to electron-hole pairs generated in the depletion region is designated as "generation current, "while that due to pairs produced outside the depletion region is termed "diffusion current." The sum of these components plus possible surface generated currents, which in some cases may be the largest component, equates to the total current. These components deserve separate and more detailed consideration. 


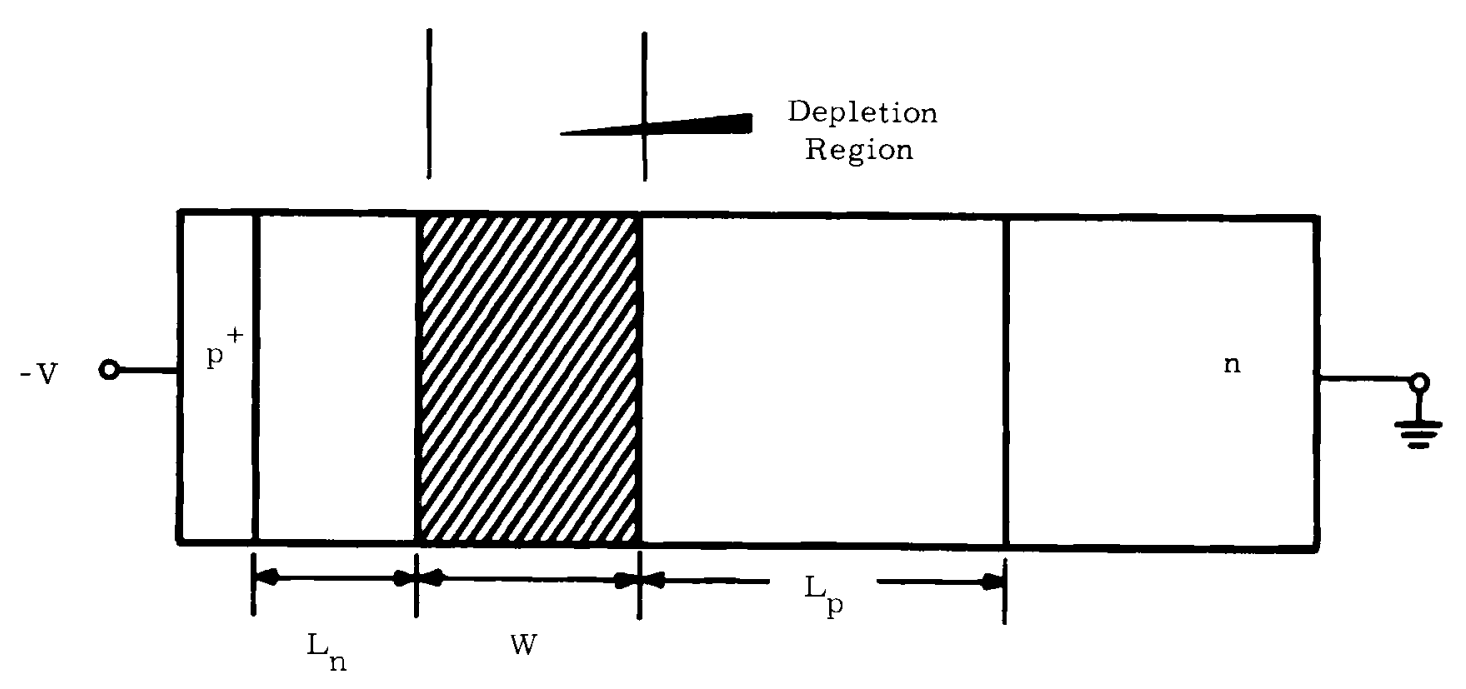

FIGURE 1. Diagram of Important Regions in $\mathrm{p}+\mathrm{n}$ Diode

For the first component (that generated in the depletion region), electron-hole pairs sweep across the depletion region very quickly because of the applied electric field. Nearly the entire bias voltage appears across the depletion region. With the carriers moving out of the region as they are generated, the carrier concentration reduces to considerably below that for equilibrium and to less than the intrinsic concentration within the semiconductor. Under these conditions, the rate of generation of electronhole pairs in the depletion region becomes that given by Grove: ${ }^{(12)}$

$$
\mathrm{U}=\frac{\mathrm{n}_{\mathrm{i}}}{2 \mathrm{~T}_{\mathrm{O}}}
$$

where $\tau_{0}=\frac{\sigma_{n} \exp \left[\left(E_{t}-E_{i}\right) / k T\right]+\sigma_{p} \exp \left[\left(E_{i}-E_{t}\right) / k T\right]}{2 \sigma_{p} \sigma_{n} v_{t h} N_{t}}$

and $\mathrm{U}=$ Rate of carrier generation per unit volume

$n_{i}=$ Intrinsic carrier concentration

$\tau_{\mathrm{O}}=$ Effective lifetime within a reverse biased depletion region

$\sigma_{n}=$ Conductivity of the $n$-region

$\sigma_{\mathrm{p}}=$ Conductivity of the $\mathrm{p}$-region

$v_{t h}=$ Thermal velocity of carriers 


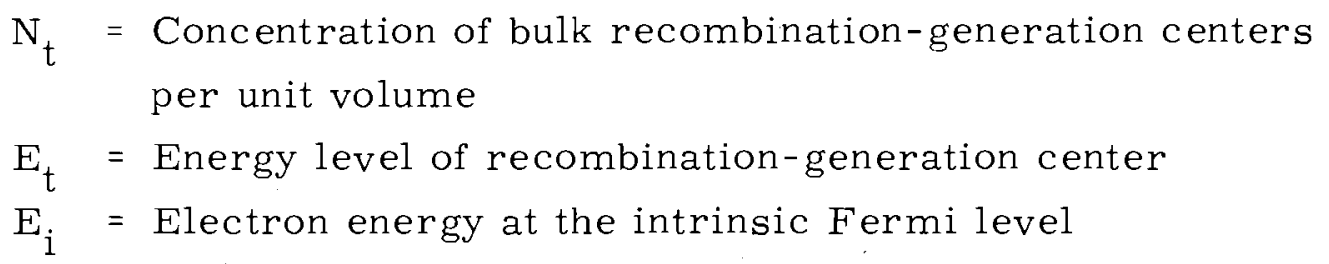

Since each generated electron-hole pair provides one electronic charge to the external circuit, the total generation current equates to

$$
I_{\text {gen }}=q \frac{\dot{n}_{i}}{2 \tau_{o}} \quad W A_{J}
$$

where $W$ is the width and $A_{J}$ the area of the depletion region. As this is the thermal generation rate, other means of generating carriers such as by external illumination will require additions to this thermal term. This component of the current relates proportionally to the depletion region width (a function of bias voltage). Consequently, the reverse current will be a function of bias voltage. This explains, in part, why the reverse current does not saturate at $I_{s}$ for a reverse bias voltage above one volt as predicted by the ideal diode equation.

The second component of the current equates to that generated in the bulk of the semiconductor outside of the depletion region. Electronhole pairs produced near the depletion region may diffuse towards the region under the influence of the concentration gradient of the majority carrier in the region. The electrons generated within a diffusion length of the depletion region on the p-side of the junction will diffuse into the depletion region to be swept to the $\mathrm{n}$-side of the region by action of the reverse bias field across the junction. A similar argument holds for holes generated in the n-region. Such concepts serve to explain the diffusion current used in deriving the ideal diode equation. In order to identify the generation rate, the equation for the saturation current with $\mathrm{V} \rightarrow \mathrm{kT} / \mathrm{q}$ must be included. For electrons generated in the p-region with thermal generation only, the saturation current becomes:

$$
I_{D, n}=q D_{n} \frac{n_{p o}}{L_{n}} A_{J}=q D_{n} \frac{n_{i} 2}{N_{A} L_{n}} \quad A_{J}=q\left[\frac{n_{p o}}{T_{n}}\right] L_{n} A_{J}
$$


where

$$
\begin{aligned}
D_{n}= & \text { Diffusivity of electrons } \\
L_{n}= & \text { Diffusion length in } n \text {-region } \\
n_{p o}= & \text { Concentration of electrons in } \mathrm{p} \text {-type semiconductor } \\
& \text { (in equilibrium) } \\
N_{A}= & \text { Concentration of acceptor impurities } \\
\tau_{n}= & \text { Lifetime of electrons in } \mathrm{p} \text {-type semiconductor }
\end{aligned}
$$

Other constants previously defined.

The bracketed term in the equation indicates the generation rate in the bulk material outside the depletion region. Similarity exists between the form of the diffusion current and the generation current, as given in Equation (4). Again, use of an external source of generation such as illumination would require an addition to the generation rate term in the preceding equation. With no dependence upon voltage in the equation, the term "saturation current" is justified. However, it is a function of $\mathrm{n}_{i}^{2}$, while the generation current relates only to $n_{i}$. Since the intrinsic carrier concentration, $n_{i}$ relates functionally to temperature, the operating temperature will have an important bearing on which component dominates the reverse current.

The third component of the current results from surface considerations. Because this extremely difficult subject has only recently received close investigation, discussion of surface effects must be rather qualitative. Minor leakage current, although occurring on the surface of the semiconductor, remains a contribution not normally considered in a discussion of current due to surface effects. The most important effects of surfaces on semiconductors relate to the rate of carrier recombination and to the breakdown voltage. Except in certain idealized cases, quantitative calculations of the magnitude of these effects can be extremely difficult if not impossible. Surfaces certainly appear to be the least easily controlled variable in the manufacturing of semiconductors. Large variations in the effects of surface conditions can be observed in devices of the same type. 
Passivation methods, in which a very thin layer of $\mathrm{SiO}_{2}$ covers the surface, enhances the stability and reproducibility of surface effects. Passivation does not, however, completely remove the effect of surface problems on the characteristics of semiconductors.

The surface of a semiconductor represents a discontinuity to the electric field, the internal space charge, and to the crystal structure in general. The surface layer of atoms has incomplete covalent bonds which produce extra allowed states for electrons within the forbidden band. The surface contaminants evidenced by practical semiconductors result in fewer or more than normal surface states or recombination centers. An additional cause of surface induced changes in device characteristics relates to the fact that ionic charges outside the semiconductor surface will induce image charges in the semiconductor, thereby producing surface space charge regions. Figure 2 illustrates the method by which charges can be induced in the semiconductor. In this case, reverse bias on the $\mathrm{p}-\mathrm{n}$ junction, by producing a positive $n$-type region and a negative $\mathrm{p}$-type region, causes collection of electrons or negative ions on the surface of the n-type region and positive ions on the p-type region. For the example device, the $\mathrm{p}$-region evidences negligible effects from the surface charge because of heavy doping. However, the $\mathrm{n}$-region has less doping and the induced charge near the surface inverts the region to a $p$-type. Such a change in the junction modifies the geometry of the depletion region and materially affects the current and breakdown voltage characteristics of the diode.

In many cases $(2,13)$ surface breakdown occurs before body breakdown and surface breakdown depends heavily on surface charge density. In fact, considerable effort must be expended to insure that uniform body breakdown occurs in devices designed to operate in avalanche. Grove has shown ${ }^{(14)}$ that very large currents can be caused to flow in $\mathrm{p}^{+} \mathrm{n}$ devices by inducing an inversion layer at the 


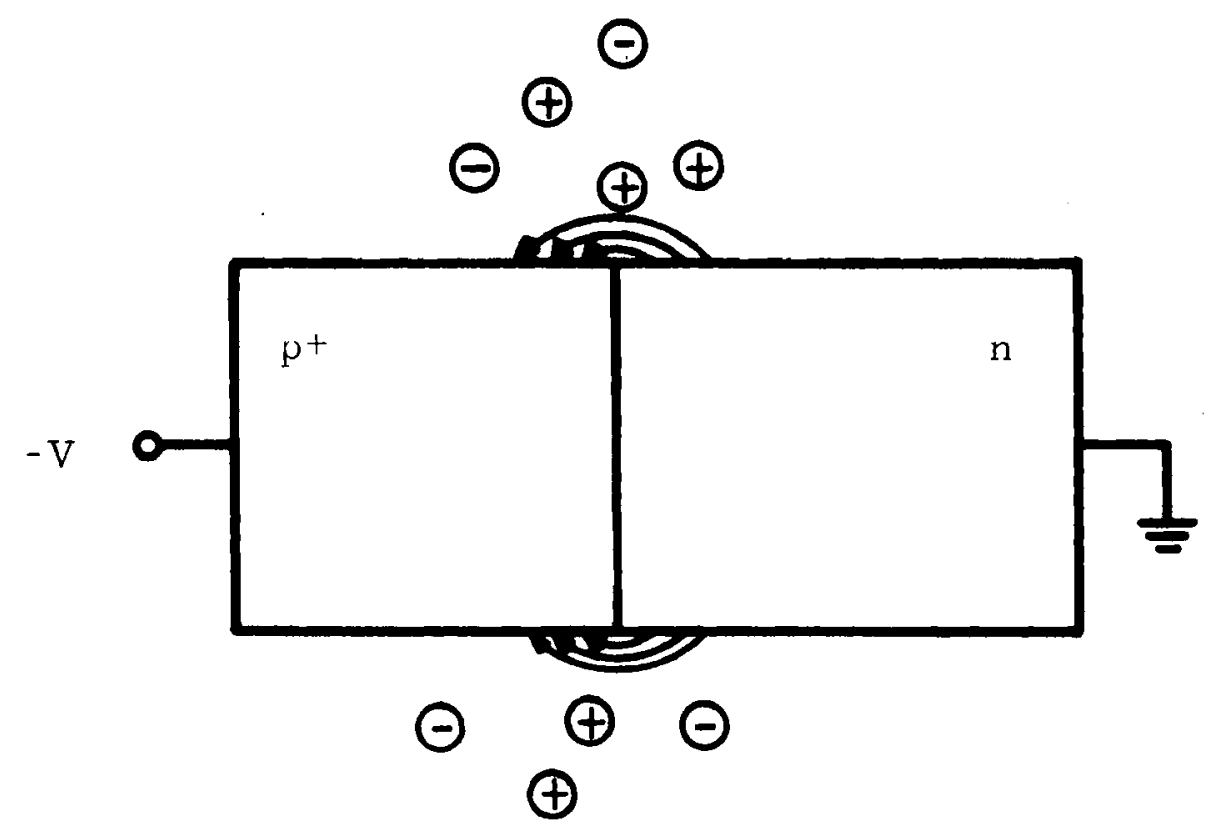

a) Reverse Biased Diode with Charged Particles in Field near Junction

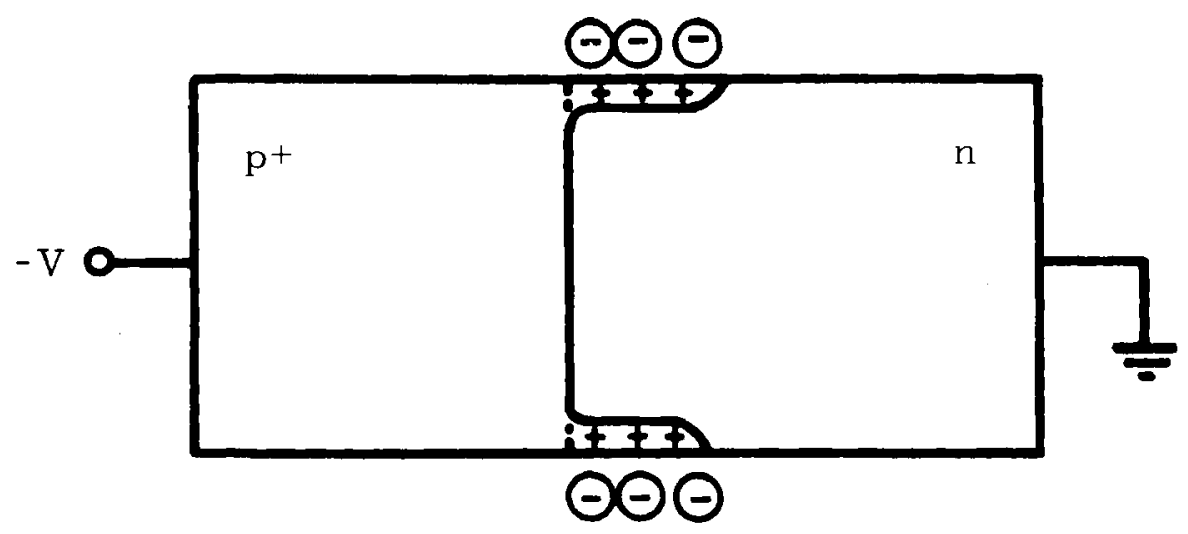

b) Resultant Inversion

FIGURE 2. Effect of Surface Charge on a $\rho_{n}^{+}$Junction 
surface of the $\mathrm{p}^{+}$-region, where this current appears to be supplied by breakdown of the induced junction near the surface. The breakdown can be either the avalanche or the Zener type.

The discussed surface effects describe only several examples of some of the important considerations. However, such important information relates directly to the experiments performed in this study because examined diodes included both passivated and nonpassivated types. In addition, the gamma irradiation will ionize the encapsulation gas and may cause surface charge buildup.

The discussion of surface effects becomes necessarily limited by the complexity of the subject and by inability to obtain significant quantitative information except for certain idealized situations. Considerable information appears in the literature, $(3,4,15)$ and the texts by J. L. Moll ${ }^{(16)}$ and by A. S. Grove ${ }^{(12)}$ provide excellent details on the subject.

The three components of current in reverse biased $\mathrm{p}-\mathrm{n}$ junctions have thus been discussed, but the characteristics in and near breakdown provide the primary interest for this report. Modifications of the relationships in the junction, in this region of operation, require considerable developmental discussion.

DIODE AVALANCHE BREAKDOWN

The application of a sufficiently large reverse bias voltage to any $\mathrm{p}-\mathrm{n}$ junction will cause breakdown, resulting in an increase in current limited only by the external circuit. Destruction of the junction can occur. Conditions necessary to initiate breakdown depend on many factors such as doping concentrations, crystal perfection, junction uniformity, and temperature. The mechanism of breakdown, analogous to that in a gas, can be rather complex in the finer details, but are rather easily explained in principle. The text by Moll ${ }^{(16)}$ provides excellent information on the details of avalanche theory, as do a number of papers in the literature. $(2,7-10)$ 
Prior to discussion of the avalanche process, it should be mentioned that the Zener effect can be confused with avalanche. In fact, Zener appears to be the common but sometimes incorrect name for a diode designed for operation in breakdown. Low voltage diodes, those exhibitng a constant voltage breakdown below about $4 \mathrm{~V}$, can be classified generally as true Zener diodes, while those above $6 \mathrm{~V}$ can be termed avalanche devices. Those diodes between 4 and $6 \mathrm{~V}$ operate by a combination of the two processes. The Zener effect stems from quantum mechanical tunneling which, in a region of extremely high electric field (approximately $10^{6} \mathrm{~V} / \mathrm{cm}$ ), causes an electron to jump from the valence band to the conduction band by penetrating through the energy gap. Since this effect relates to field strength, it can occur in very thin junctions across which the total voltage is too low to impart sufficient energy to an electron to form an electron-hole pair, the mechanism responsible for avalanche breakdown. Since the Zener process depends on the band gap energy and since the band gap becomes narrower at higher temperature, the increase in tunneling probability will produce a negative temperature coefficient for breakdown voltage. A more easily understood explanation for the effect centers on the fact that, under high field conditions, some of the covalent bonds of the crystal will come apart, thus producing conduction electrons and holes. The Zener effect occurs only when very high doping concentrations, usually above $10^{18} / \mathrm{cm}^{3}$, exist. Since this paper deals with operation near avalanche breakdown, the subject of Zener breakdown will not be investigated further.

The avalanche effect manifests itself by an increase in the reverse current as the applied voltage increases until, at some voltage, the current increases very rapidly, limited only by the external circuit. The voltage at which this increase occurs is termed the breakdown voltage, while the current increase mechanism is termed the avalanche process. The phenomenon occurs when minority carriers generated in the depletion region or those which diffuse in from the region outside become accelerated sufficiently to produce another electron-hole pair 
by an ionizing collision. The new electron and hole may also acquire sufficient energy to produce another ion pair and so on, resulting in avalanche multiplication. The multiplication occurs below breakdown, as evidenced by an increase in a reverse current over that predicted by diode reverse current theory. Figure 3 illustrates the deviation in the reverse characteristic due to avalanche multiplication. The normal predicted reverse current is multiplied by the factor $M$ as the voltage approaches breakdown voltage where this factor, relating to the applied voltage, increases with voltage until at breakdown it is infinite. Since this paper details the study of radiation effects on avalanche diodes operating near breakdown, the importance of avalanche multiplication becomes obvious.
$\mathrm{V}_{\mathrm{R}}$
$\mathrm{V}_{\mathrm{B}}$
0

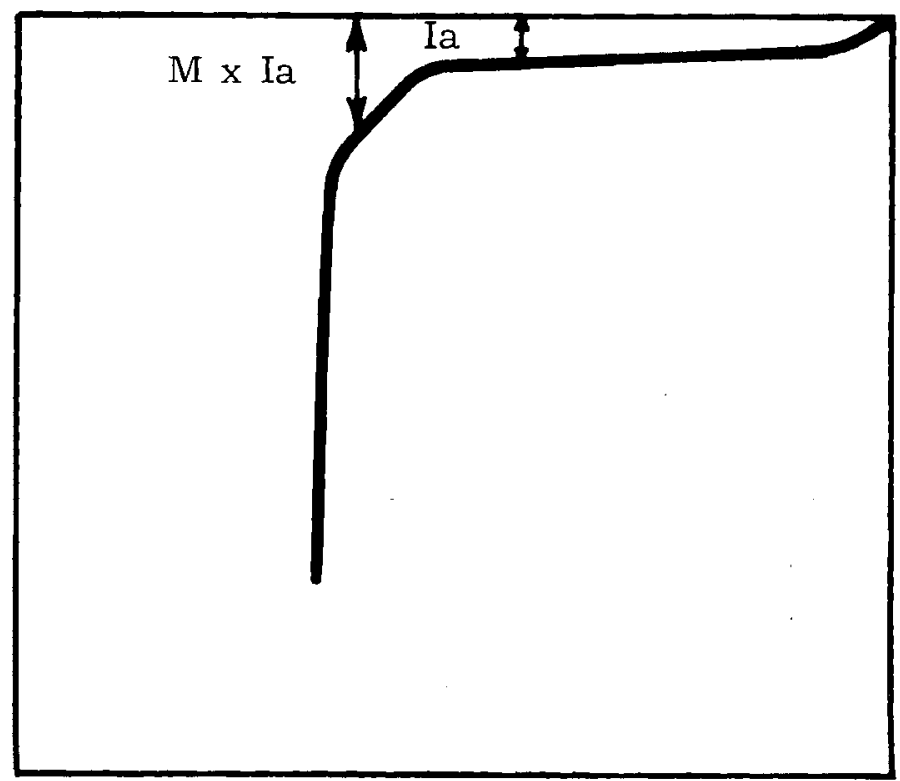

$\operatorname{Ir}$

FIGURE 3. Typical Reverse V-I Characteristic Showing the Effect of Multiplication

The derivation of the equations to provide a good model of the avalanche process become lengthy and will not be carried out here but will be discussed in general. 
Considering the ionizing carrier to be a hole entering the region from the $n$-type material, the following expression describes the avalanche mechanism in the depletion region:

$$
1-\frac{1}{\bar{M}}=\int_{0}^{W} \alpha_{n} \exp \left[\int_{0}^{W}\left(\alpha_{n}-\alpha_{p}\right) d x^{1}\right] d x
$$

where

$$
\begin{aligned}
M= & \text { Ratio of holes collected at } \mathrm{p} \text {-side of junction for } \\
& \text { each hole emitted from } \mathrm{n} \text {-side - the multiplication } \\
& \text { factor } \\
\alpha_{n}= & \text { Number of electron-hole pairs } / \mathrm{cm}^{3} \text { produced by an } \\
& \text { ionizing electron per unit distance traveled } \\
\alpha_{p}= & \text { Number of electron-hole pairs } / \mathrm{cm}^{3} \text { produced by an } \\
& \text { ionizing hole per unit distance traveled } \\
\mathrm{w}= & \text { Width of depletion region } \\
\mathrm{x}= & \text { Distance from } \mathrm{p} \text {-type region (terminal side of depletion } \\
& \text { region) } \\
\mathrm{x}^{1}= & \text { Dummy variable of integration }
\end{aligned}
$$

It has been shown ${ }^{(7-9)}$ that the ionization rates for holes and electrons are not equal. For this simplified description, how ever such equality will be assumed. Thus, the above expression reduces to

$$
1-\frac{1}{\bar{M}}=\int_{0}^{W} \alpha_{e} d x
$$

where

$$
\alpha_{e}=\alpha_{n}=\alpha_{p}
$$

When the integral in this expression equals one, M equals infinity and the device will be in breakdown. It can be shown that the integral equals the probability that one carrier will produce one electron-hole pair in crossing the depletion region. Clearly, if this probability equals one and if the ionization rates of holes and electrons are the same, a sustained avalanche breakdown will exist. 
Miller $(17,18)$ showed that the probability, $P$, and therefore the multiplication, $M$, depend on the reverse bias, $V_{r}$, and that a reasonable fit to experimental data can be given by

$$
\mathrm{P}=\left(\frac{\mathrm{V}_{\mathrm{r}}}{\mathrm{V}_{\mathrm{B}}}\right)^{\mathrm{n}}
$$

where $\mathrm{n}$ is an empirical constant, $\mathrm{V}_{\mathrm{B}}$ the breakdown voltage, and $\mathrm{V}_{\mathrm{r}}$ the bias voltage. This relation depends on several assumptions not true very close to breakdown. Without some simplifications, however, solutions to the equations cannot be obtained. Several other simplifications occur in the literature where the validity becomes subject to limitations described by Moll. (16) The stated relationship holds reasonably well up to within a few percent of breakdown and will be used here. Since the probability equaled the integral in Equation (7), appropriate substitution results in the following expression for the multiplication, as subject to the qualifications mentioned.

$$
\mathrm{M}=\frac{1}{1-\left(\frac{\mathrm{V}_{\mathrm{r}}}{\mathrm{V}_{\mathrm{B}}}\right)^{\mathrm{n}}}
$$

The value of $n$ usually ranges between 3 and 6 for silicon diodes. Figure 4 illustrates a plot of this function for several values of $n$. The resemblance to the shape of a diode $\mathrm{V}$-I characteristic near breakdown is clear.

The positive temperature coefficient of breakdown voltage becomes of some interest in the consideration of avalanche multiplication and breakdown. As the temperature of the crystal increases, the mean free path of an electron or a hole decreases, thus decreasing the probability of a carrier producing a new ion pair before recombination. A small increase in voltage to compensate for the reduction in ionization probability is therefore required. This temperature effect is opposite to that in a Zener diode. 


\section{M}

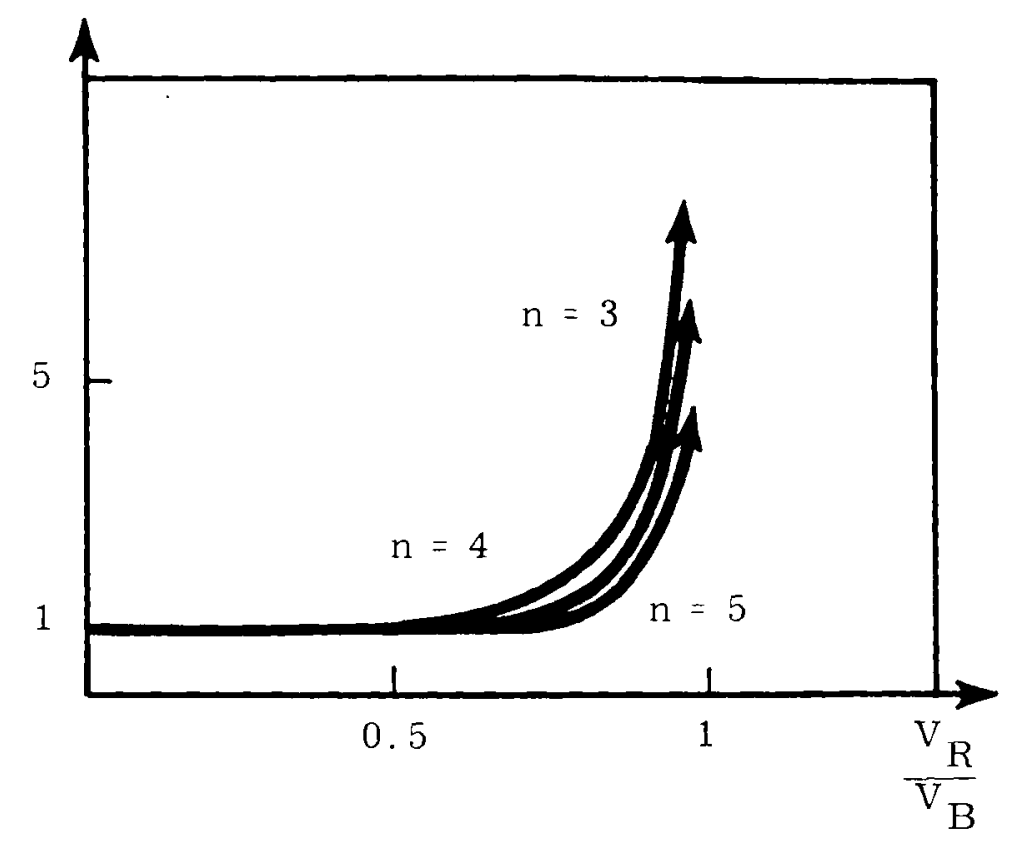

FIGURE 4. Multiplication as a Function of Normalized Bias Voltage for Various $n$

Also of interest and in violation of one of the assumptions made in obtaining Equation (9) is that the ionization rate for electrons exceeds that for holes in silicon at all reverse voltage values below breakdown. This discrepancy, although worthy of note, demonstrates insufficient importance for consideration in the development given here.

\section{EFFECTS OF RADIATION ON p-n JUNCTIONS}

Radiation effects on $\mathrm{p}-\mathrm{n}$ junctions can be classified into transient and permanent types. These types are not to be confused with the time characteristics of the radiation field. The time characteristics of the radiation field are of considerable importance under certain circumstances, particularly in the study of weapons-oriented pulse radiation damage studies. In many cases, the effect of the pulsed radiation environment $w i l l$ be total or partial device destruction, not because of the accumulated radiation 
exposure, but rather because of the extremely high rate of energy absorption. The studies of interest in this report focus on those observed in a time-invariant radiation field.

The classification of radiation effects as either transient or permanent depends on whether the effects disappear after removal of the device from the field. Permanent effects generally involving permanent damage or changes in the crystal structure are usually caused by interactions with neutrons or specific high energy particles. Photon interactions within the crystal do not produce nuclear or atomic displacements and therefore do not normally produce permanent effects. Since the experiments described in this report involve only gamma irradiation, the anticipated effects should be transient in nature.

When X-rays or gamma rays interact with matter, three predominant mechanisms occur: photoelectric, Compton, and pair production. The total absorption coefficient sums the absorption coefficients of each of the three processes, where each must be considered separately for a given material. Frank ${ }^{(1)}$ derives and calculates each for silicon, and only the important results will be included here.

The photoelectric process becomes important for photon energies below $50 \mathrm{keV}$ in silicon and involves total absorption of the incident photon with all its energy consumed in the ejection of an electron from an atom. For ${ }^{60}$ Co gamma irradiation with an average photon energy of $1.25 \mathrm{MeV}$, this process is of negligible interest and will not be considered further.

Compton scattering becomes important for photon energies of $50 \mathrm{keV}$ to $15 \mathrm{MeV}$ in silicon. This process involves separation of an electron from its atom with the simultaneous emission of another photon of different energy. The electron liberated in this way can produce more electron-hole pairs by ionization. The absorption coefficient for ${ }^{60} \mathrm{Co} 1.25 \mathrm{MeV}$ photons in silicon equates to $0.132 / \mathrm{cm}$ and can be regarded as the probability that a photon will be scattered per centimenter of 
silicon or relative measure of the energy absorbed per centimeter. This absorption term is the most important for ${ }^{60} \mathrm{Co}$ irradiation of silicon.

In pair production, a gamma ray with sufficient energy enters the coulomb field of a nucleus to create an electron-positron pair. This pair creation cannot occur at photon energies below $1.02 \mathrm{MeV}$ because this amount of energy must be available to supply the rest energy of the two particles created. This process at photon energies above $15 \mathrm{MeV}$ becomes more important than the Compton effect, but pair production need not be considered at the ${ }^{60}$ Co energies involved in these experiments.

The number of electron-hole pairs generated by gamma rays in silicon becomes of some importance in the following discussions. Assuming the total absorbed gamma ray energy to be used in the production of electron-hole pairs, the following relations become of interest: ${ }^{(1)}$

$$
G_{\gamma}=N_{\gamma} \frac{\mu \bar{E}_{C}}{E}
$$

where $\mathrm{G}_{\gamma}=$ Generation rate in electron-hole pairs $/ \mathrm{cm}^{3}-\mathrm{sec}$

$\mathrm{N}_{\gamma}=$ Number of gamma quanta incidence/unit area and unit time

$\mathrm{E}=$ Energy to produce one electron-hole pair (3.625 in silicon)

$\mu=$ Linear absorption coefficient $\left(0.13 \mathrm{~cm}^{-1}\right)$

$\overline{\mathrm{E}}_{\mathrm{C}}=$ Average energy of Compton electrons

The primary effect to be noted for reverse biased diodes will be an increase in the current due to the generation of electron-hole pairs as described by the equation. The electron-hole pair generation due to ${ }^{60} \mathrm{Co}$ gamma irradiation in a field of $2 \times 10^{6} \mathrm{R} / \mathrm{hr}$, the level for experiments of this report will exceed the thermal generation term by a considerable amount as will be shown later in the experimental description portion of this report. For this reason, the gamma generation term, Gr, will replace the thermal generation term in Equations (4) and (5), which predicted the reverse bias current. In addition to this, the true current for operation near breakdown will be larger than the predicted current by the 
multiplication factor, $M$, as discussed previously. The predicted current will be

$$
I_{R}=I_{g}+I_{d}+I_{s}=q G \gamma\left(L_{p}+L_{n}+W\right) A_{J}+I_{s}
$$

and near breakdown with multiplication factor $M$,

$$
I_{B}=M\left[q G_{\gamma}\left(L_{p}+L_{n}+W\right) A_{J}\right]+I_{s}
$$

Allowing for only electron-hole generation effects in silicon, the measured current should be constant throughout the irradiation as long as the gamma field remains constant. The current $I_{R}$ can be measured much below breakdown where $M$ approaches unity, and the current at the selected bias $\mathrm{I}_{\mathrm{B}}$ will provide the multiplication factor $\mathrm{M}$ if $\mathrm{I}_{\mathrm{S}}$ is small. The question then relates to what, if any, added effects of the irradiation could cause the value of the current to change under irradiation. If any of the more permanent effects such as defect generation and trapping should occur, the current could be changed. Further, if surface effects play any important role in the process, I could change. This possibility certainly looms as an important but unpredictable consideration. Perhaps it would be expected that the passivated devices should show less, or at least more constant, effects if surface consideration becomes an important mechanism. Another possibility, a change in the breakdown voltage, could produce a change in the multiplication factor. For some insight into the possibility of occurrence of these problems, observations of other investigations will be cited.

Bulk effects considerations involve ionization current due to gamma generation. The only mechanism capable of producing either current changes under constant exposure rate conditions or persistent postirradiation changes in the device characteristics would be defect generation, which essentially increases the number of recombination centers. This effect modifies the minority carrier lifetime and mobility. Since gamma ray interactions with the nucleus appear negligible, it might seem that 
no defects should occur. However, the Compton electron generated by the gamma ray can interact with the nucleus and, according to Frank, produce a significant number of Frenkel defects (vacancy-interstitial pairs). Frank concludes that such a mechanism can be responsible for permanent effects from gamma irradiation, as observed in a series of experiments conducted on reverse-biased silicon diodes. The Frenkel defect mechanism includes donors and acceptors as well as recombination centers. This explanation of the observed effects does offer a reasonable explanation of Frank's results, but most others ${ }^{(3,4)}$ place little significance on bulk defect generation by gamma rays. Mitchell points out the strong evidence that the vacancy-interstitial pairs engage in immediate self-annihilation.

Recently, many investigators concentrating primarily on surface effects, have concluded that such radiation effects are of greater importance than bulk effects in modern diffused silicon devices. Mitchell ${ }^{(3)}$ discusses this point in some detail in his excellent review paper on surface effects. One of the earliest and most publicized examples of device failure as a result of radiation-induced surface effects occurred in the Telstar satellite in November 1962. ${ }^{(3)}$ The failure apparently resulted from radiation-induced surface effects caused by radiation in the Van Allen Belt. Laboratory experiments determined that changing the bias on the suspected transistors would speed recovery. Accomplishment of this by special commands to the satellite aided prompt recovery.

Since the experiments described in this report used both passivated and nonpassivated diodes, some observations about the possible surface effects on each can be discussed. Basically, the cause of the surface effects on both types of devices can be classified as charge buildup or migration, either on the surface or in the surface coating. The predominant effect on the device of this charge buildup will be formation of surface channels, which can degrade the characteristics of the semiconductor. Mitchell notes that, in some cases, surface effects of 
radiation on nonpassivated devices becomes noticeable at absorbed energy of about $10^{3}$ rads. In general, the accepted mechanism for charge buildup on nonpassivated surfaces seems to be ionization of the encapsulation gas with subsequent collection and separation of the charges by the field existing across the reverse-biased junction. Figure 2 illustrates the effect. The important parameter variation in diodes as a result of surface charge buildup appears to be degradation in reverse bias leakage currents. The amount of degradation and the rate of recovery depends on the bias voltage, with forward bias usually accelerating recovery.

Most studies of surface effects on semiconductors have been conducted with $\mathrm{SiO}_{2}$ passivated planar devices. While a considerable amount of information exists in the literature, little agreement appears at this time among investigators. One major point of disagreement concerns the locations and mechanism of charge buildup on the surface. Atalla ${ }^{(19)}$ has proposed a model quite similar to the one used for nonpassivated diodes in which mobile charge carriers on the surface of the $\mathrm{SiO}_{2}$ layer migrate under the influence of the electric field across the junction. For severe charge separation, the semiconductor surface near the oxide will invert, and formation of channels in a manner similar to that for the nonpassivated devices will result in a reverse current increase. Another proposed model, supported by the work of Mathews, et.al. , ${ }^{(20)}$ shows the important mechanism to be charge storage and transport within the oxide. These charges, accumulating near the oxide-silicon interface, greatly influence the surface potential and characteristics of the device. All investigators agree to the very important role played by the $\mathrm{SiO}_{2}$ layer in radiation effects of passivated devices and also believe that the observed effects equate to those in nonpassivated devices, apparently as a result of the same surface charge and channel generation mechanism. Mitchell ${ }^{(3)} \mathrm{com}-$ pared passivated devices with similar varnish-protected silicon "mesa" diodes and found the degradation in the oxide-covered diodes to be an order of magnitude less. 
Grove has published considerable information regarding surface effects on passivated devices, but most of his work utilized gate controlled devices. The presence of the gate electrode on the oxide surface permits positive charge buildup in the oxide layer by removal of the electrons via the gate electrode. This mechanism cannot be achieved in normal passivated diodes and must, therefore, be taken as inconclusive with regard to radiation effects for diodes. Yamin ${ }^{(21)}$ demonstrated that charge buildup in the oxide occurs only in that portion of the oxide under a metal electrode through which charge may be withdrawn. Available evidence indicates the probability of charge buildup either in the oxide or on its surface, depending on the experimental assembly, the source of the charge, and the mechanical configuration of the tested device.

Surface effects for avalanche diodes may be less pronounced than in ordinary devices because of particular consideration to surface design and treatment required to assure the occurrence of uniform breakdown needed for proper operation. Since surface breakdown often occurs at lower voltages than bulk breakdown, special manufacturing steps control the surface characteristics. One such step is the surface contouring of high voltage, charge multiplying radiation detectors.

\section{EXPERIMENTAL PROCEDURE}

The experiments described in this report were focused on the response of six passivated and seven nonpassivated avalanche diodes biased in or near breakdown to ${ }^{60}$ Co gamma irradiation. The diodes were Motorola 1N2846, $200 \mathrm{~V}, 50 \mathrm{~W}$ devices. Ten devices of each treatment type (all with the same type number) were obtained initially. However, two nonpassivated and three passivated devices proved unsuitable because of high leakage currents or premature microplasma breakdown. One good device of each type provided experimental control (no irradiation). Reverse bias V-I curves were measured before, during, and after irradiation, and reverse current recordings were made throughout the irradiations with the diodes biased $5 \%$ below 
breakdown. Six experiments utilized encapsulated devices, while four experiments followed with encapsulation removed and with a vacuum placed on the system.

\section{GAMMA FACILITY}

The experimental gamma facility at Battelle-Northwest contains about $300,000 \mathrm{Ci}$ of ${ }^{60} \mathrm{Co}$ centered in a circular array at the bottom of an $8 \mathrm{ft}$ diam tank filled with $13.5 \mathrm{ft}$ of water.

Figure 5 shows the tank with the test chamber and tube assembly on the left side of the center supports. The experiments were performed in a 2 in. diam stainless steel tube welded closed on the end and placed in the water. A machined lead brick prevented movement of the bottom of the tube.

The chamber shown on the top of the tube provided the vacuum interface through which electrical connections were made to the system during vacuum operation. Coaxial cables and thermocouples connected inside the chamber to standard BNC connectors. The cables connect to the probe containing the diode under experiment, and the thermocouple attaches directly to the diode case.

Figure 6 shows the diode holder assembly, constructed of $3 \mathrm{ft}$ long nylon rods with diode mounting assembly located 7 in. from the bottom (the elevation of maximum gamma intensity). The length of the probe allows positioning of the coaxial cables and connectors in a lower flux region, thus reducing possible degradation. Gamma intensity at the $3 \mathrm{ft}$ elevation measures two orders of magnitude lower than at the $7 \mathrm{in.}$ position.

The radiation field, as measured by a commercial ion chamber probe and ratemeter, proved to be $2 \times 10^{6} \mathrm{R} / \mathrm{hr}$. Figure 7 shows the gamma profile, and the location of the test assembly is marked with an " $\mathrm{X}$ " (about $10 \mathrm{in.}$ from the source). 


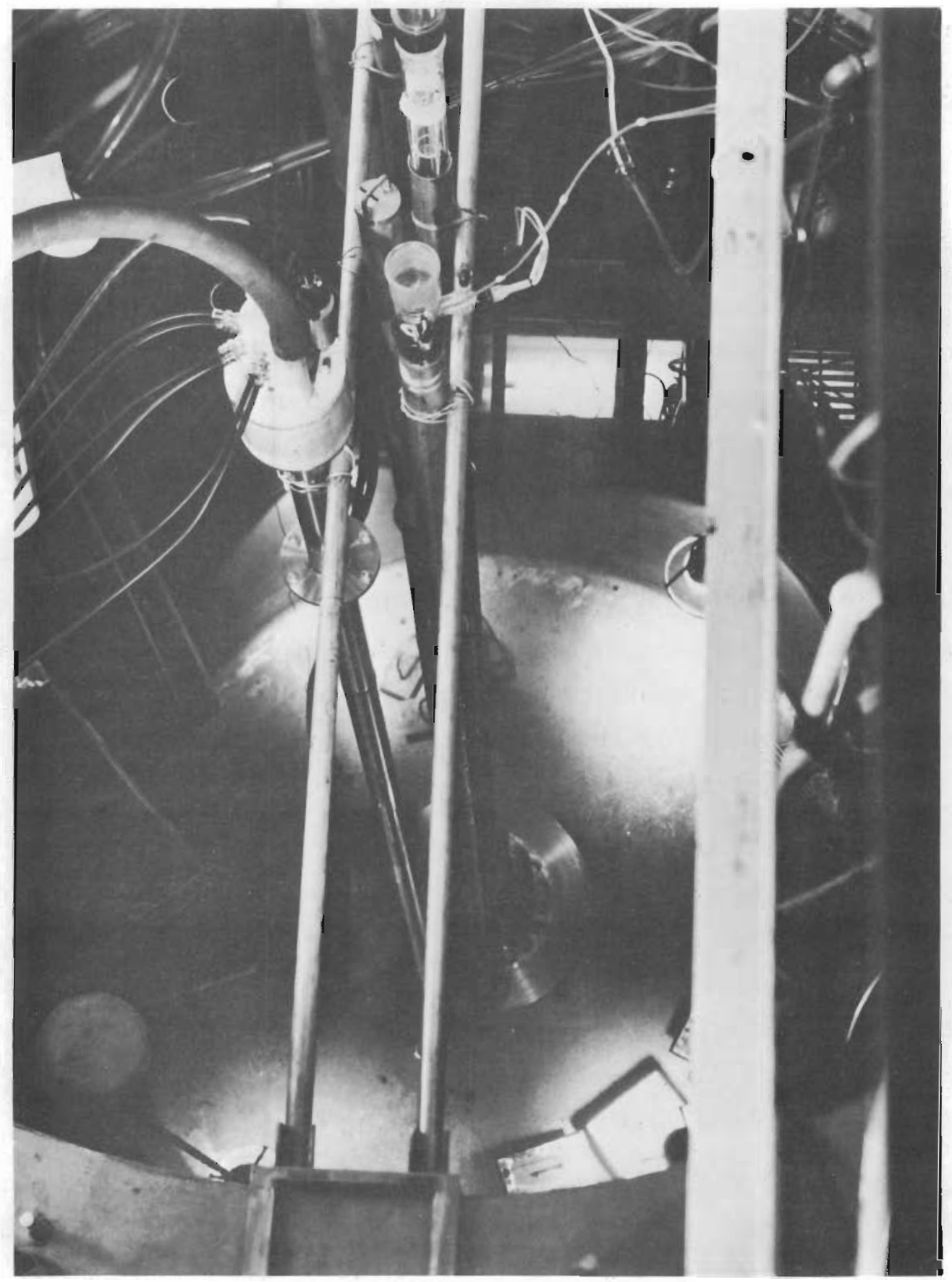

Neg PNL-0672317-11 


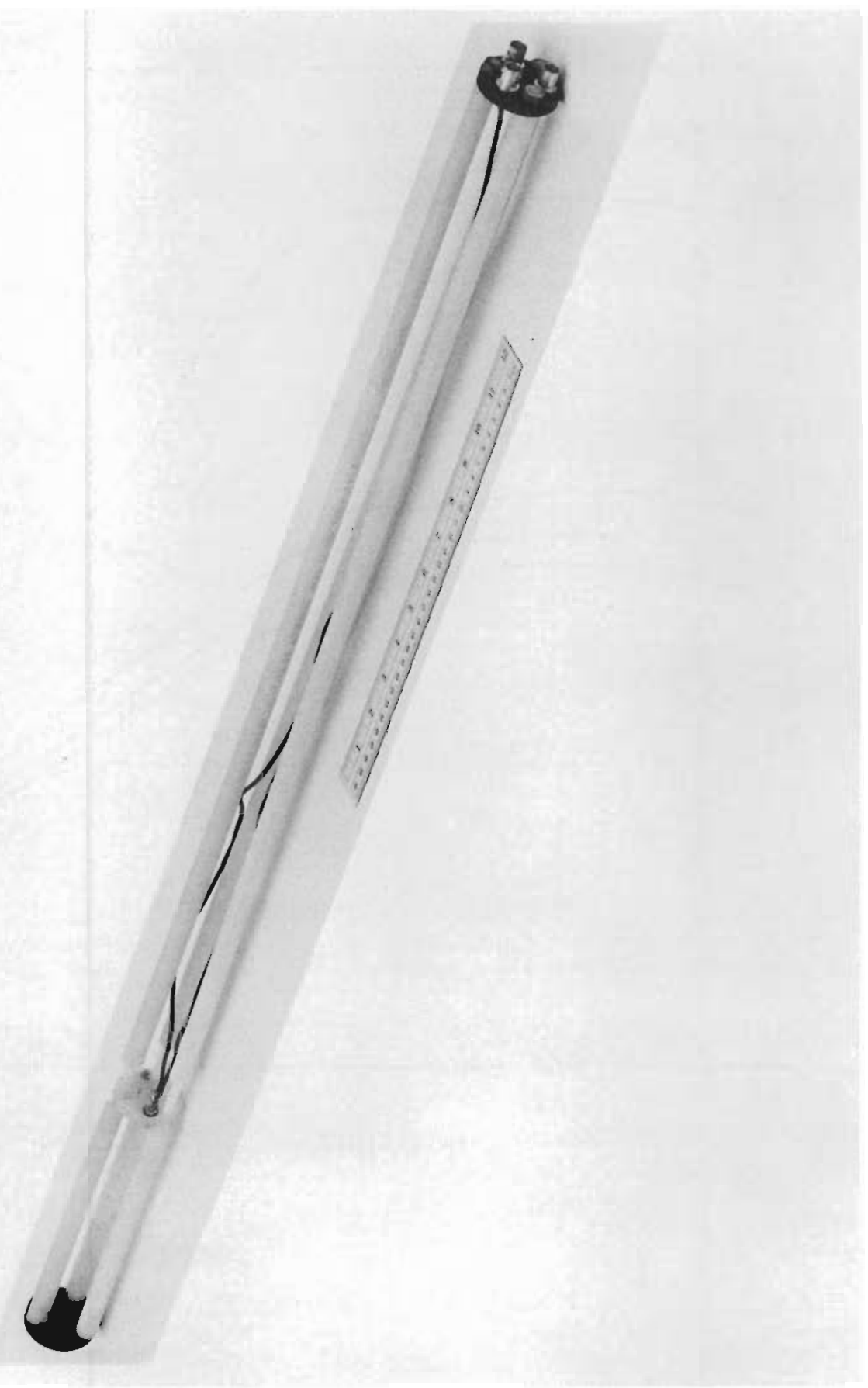

Neg PNL-0681571-1

FIGURE 6. Diode Test Holder Assembly 


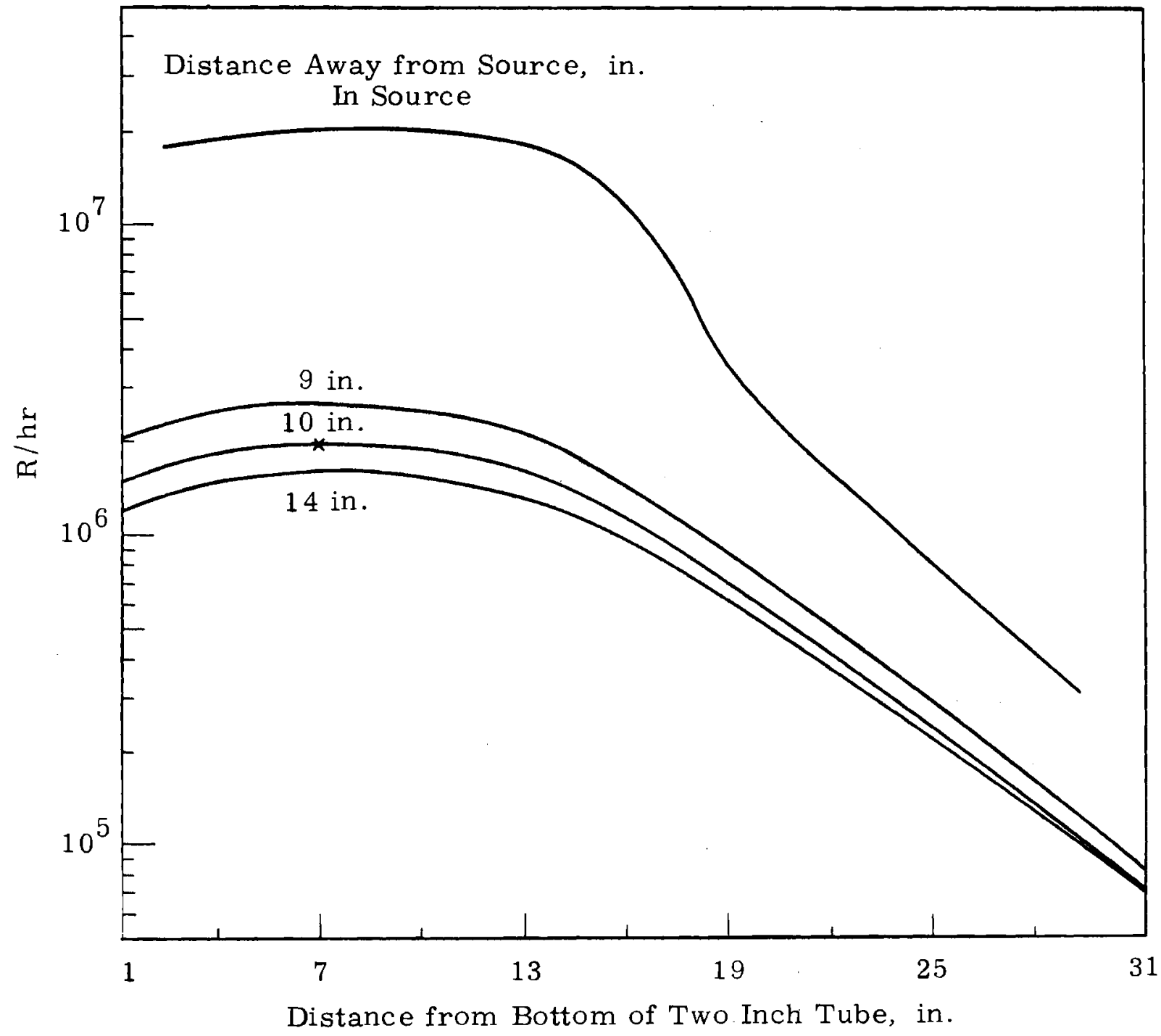

FIGURE 7. Gamma Flux Profiles 


\section{INSTRUMENTATION}

Commercial instrumentation, shown schematically in Figure 8, was used for all measurements. A 1 rpm motor varied the power supply over its full range from 0 to $320 \mathrm{~V}$ to allow plotting of the reverse bias V-I characteristics. The switching arrangement for the "run" position shorts the inputs to the X-Y recorder while, in the "plot" position, the input to the strip chart recorder is shorted to ground. The metering and current limiting resistors require no explanation. The digital voltmeter provided continuous monitoring of the voltage across the diodes and bias voltages were set and maintained with this measurement rather than with the recorder measurement. An ironconstantan thermocouple and a commercial calibrated readout instrument provided temperature measurements, while a thermocouple device permitted vacuum determinations.

MEASUREMENT PROCEDURE

The measurement procedures used in these experiments can be divided into preirradiation, during irradiation, and postirradiation (recovery) conditions. Chart recordings provided permanent information during a majority of the tests, with manual methods employed for the remainder of the data.

Figure 6 illustrates the diode holder assembly in which the diode was mounted during the experiments. An $X-Y$ recorder plotted the reverse bias V-I curves, and a digital voltmeter measured the breakdown voltage before irradiation. Application of the desired reverse bias voltage, $95 \%$ of the breakdown level, provided the preirradiation bias current as indicated on the calibrated chart recorder.

Following the preirradiation measurements, the diodes were lowered to the bottom of the $2 \mathrm{in}$. tube in the gamma facility to initiate the irradiation tests. During irradiation, application of voltage in a continuous manner from zero volts to breakdown permitted acquisition of V-I curve information. Reduction of the voltage to the desired 


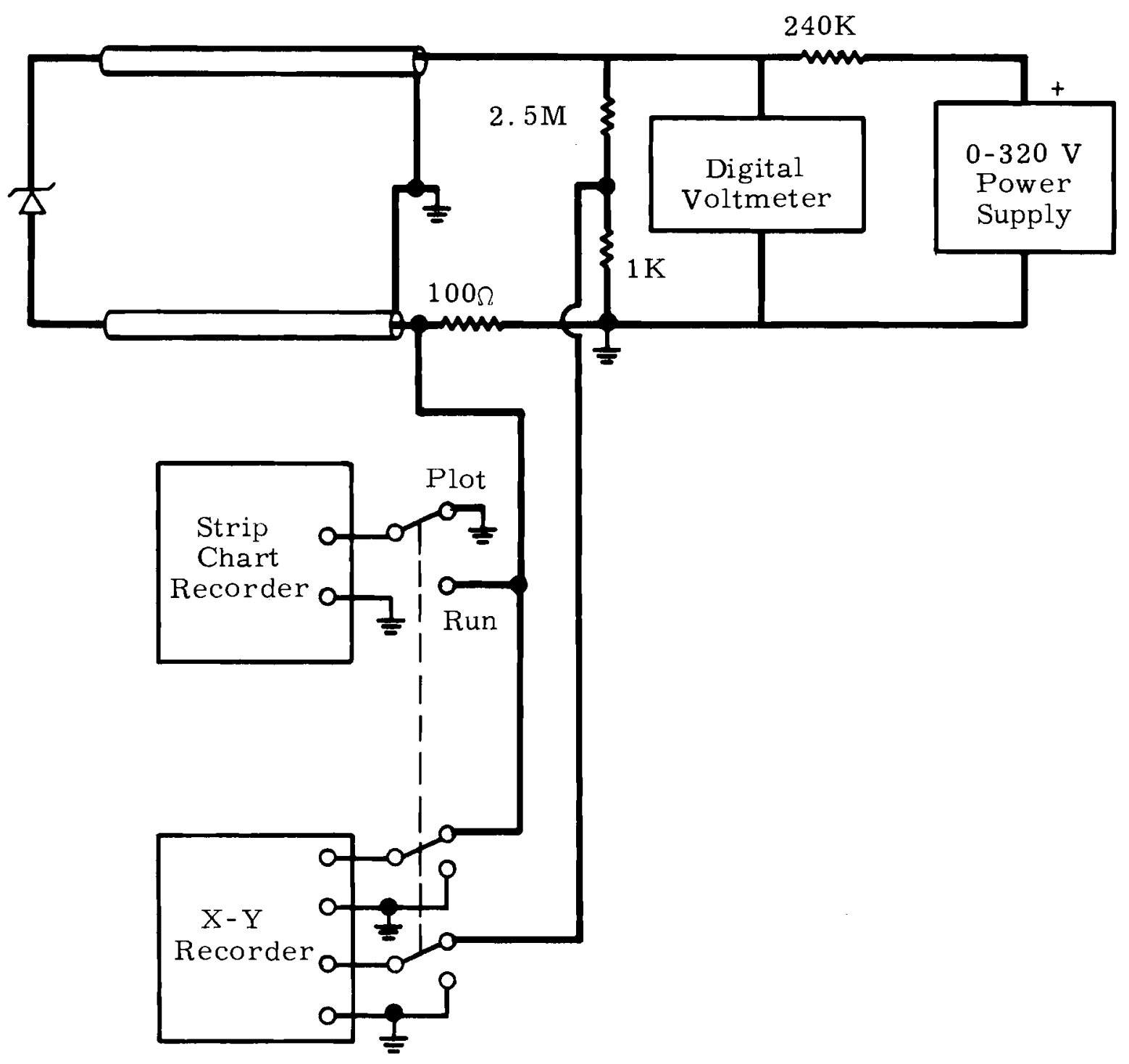

FIGURE 8. Test Instrumentation 
operating bias, as indicated on the digital voltmeter, and movement of the function switch to the "run" position provided a continuous strip chart recording of the reverse current. Manually recorded temperature measurements of each diode occurred at 2 min intervals, while V-I curves were obtained at 5 min intervals for $10 \mathrm{~min}, 10 \mathrm{~min}$ intervals for 20 min, and once per hour thereafter. For a diode without encapsulation, the procedure remained substantially the same, except for the use of a vacuum pump to maintain proper conditions.

Following completion of the irradiation with each diode, the test assembly was removed from the tube with the bias voltage maintained. Measurement of the reverse current was continued with V-I curves and temperature measurements obtained at the same previously described intervals. Such measurements were continued until the diode either recovered or attained some equilibrium condition. Another test $24 \mathrm{hr}$ later revealed any changes in recovery characteristics.

When warranted by specific conditions observed during the tests, certain procedural deviations permitted the acquisition of special data pertaining to diode operation. The usual experiment for each diode encompassed $24 \mathrm{hr}$. However, several $72 \mathrm{hr}$ tests were conducted over weekends with selected units.

\section{$\underline{\text { RESULTS }}$}

A number of irradiation effects, some individual and others more general, were observed on the diodes tested in these experiments. Because any conclusions would be quite difficult to establish as a result of effects noted on a single diode, reporting of the individual effects and irregularities will be minimized and emphasis placed on effects observed on all the diodes or on all of one type. Differences between passivated and nonpassivated diodes will receive particular emphasis.

Except for the occurrence of microplasma noise, performance of the passivated diodes can be generally described as consistent with the mathematical models. The nonpassivated devices on the other hand, 
performed in a less predictable manner. Although some differences exist in the construction of the diodes, the most significant difference is that of surface treatment. In fact, irradiation effects on the nonpassivated units logically appear to be almost entirely of surface origin. In addition, this could be the cause of the microplasma in the passivated diodes. A further examination of the results will be presented following discussion of anticipated performance, as predicted by the models discussed earlier in this report.

The appendix details physical dimensions, impurity concentrations, fabrication methods, and specifications of the diodes. Part of this information will be required to solve the equations used to describe the diode operation, but observed measurements must be used to determine some of the parameters required in the models. It would be interesting to calculate the value of the predicted multiplication factor $\mathrm{M}$ from Equation (9). This equation, however, gives poor results (within 5\% of breakdown) especially for silicon. For this reason, the values of multiplication will be obtained from the recorded results as the ratio of the measured current at the chosen bias to that at a voltage significantly lower.

As an example of the multiplication factor predicted with $\mathrm{n}=3$ (a typical value from Grove) and with $\left(\mathrm{V}_{\mathrm{r}} / \mathrm{V}_{\mathrm{B}}\right)=0.95$, IM will equate to 7. The expression for the reverse current below the multiplication region, previously given by Equation (11), follows herewith for reference.

$$
I_{R}=q G_{Y}\left(L_{n}+L_{p}+W\right) A_{J}+I_{s}
$$

In this equation, $G_{Y}$ symbolizes the generation rate of electron-hole pairs (almost completely due to the gamma irradiation) and can be calculated with Equation (10) given earlier. Using these equations for $2 \times 10^{6} \mathrm{R} / \mathrm{hr}$ ${ }^{60}$ Co gamma field, 


$$
G_{Y} \cong 2 \times 10^{16} \frac{\text { electron-hole pairs }}{\mathrm{cm}^{3}-\mathrm{sec}}
$$

The area of each diode is equated to $0.0144 \mathrm{in}^{2}$ or $0.093 \mathrm{~cm}^{2}$. The diffusion length, $\mathrm{L}_{\mathrm{p}}$, for holes in the lightly doped $\mathrm{n}$ material will be much longer than $L_{n}$, the equivalent length for electrons in the heavily doped $\mathrm{p}^{+}$region. The width of the depletion region is approximately $1 \mu \mathrm{m}$ at voltages below $10 \mathrm{~V}$. (12) Ignoring the surface term for the present, one can calculate $\left(L_{p}+W\right)$ by measuring and substituting the current at low voltage in the preceding equation. A typical value of current measured below $10 \mathrm{~V}$ bias was about $1.5 \mathrm{\mu A}$ shortly after entry into the gamma field. Use of this value results in $50 \mu \mathrm{m}$ for the diffusion length.

Differences between the passivated and nonpassivated diodes do not appear sufficient to predict differences in current in the gamma field. However, the impurity concentrations are slightly different for the two types and different surface treatments are used. These characteristics, however, will not result in significant current differences.

The predicted current, initially estimated by using the approximate multiplication factor of 7 and the typical low voltage reverse current of $1.5 \mu \mathrm{A}$, shows the current at the operating bias of $0.95 \mathrm{~V}_{\mathrm{BD}}$ to be

$$
I=M I_{R}=7 \times 1.5 \mu A=10.5 \mu \mathrm{A}
$$

The theory provides no predictions regarding effects other than the multiplied gamma generation current. How ever, the consideration concerning possible surface effects leaves open other possibilities.

In considering some actual results, Figure 9 depicts data reconstructed from the continuous current recordings. Because the time scale compression obscures the required detail to some extent, the figure shows only the more significant events of four representative experiments. Experiments 5 and 6 used irradiated nonpassivated 


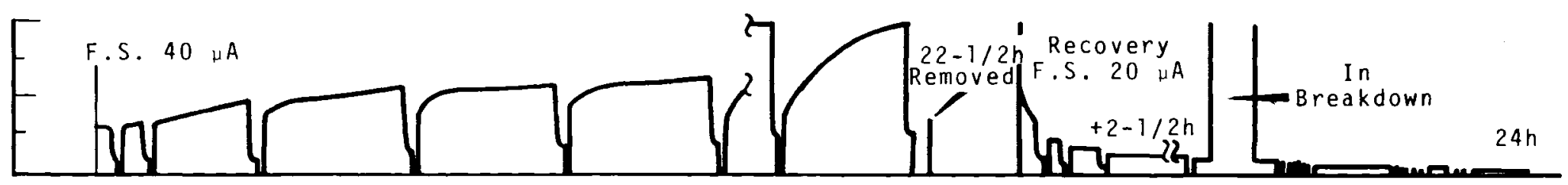

a) Experiment 5, Non-Passivated Diode Numberlo with Encapsulation

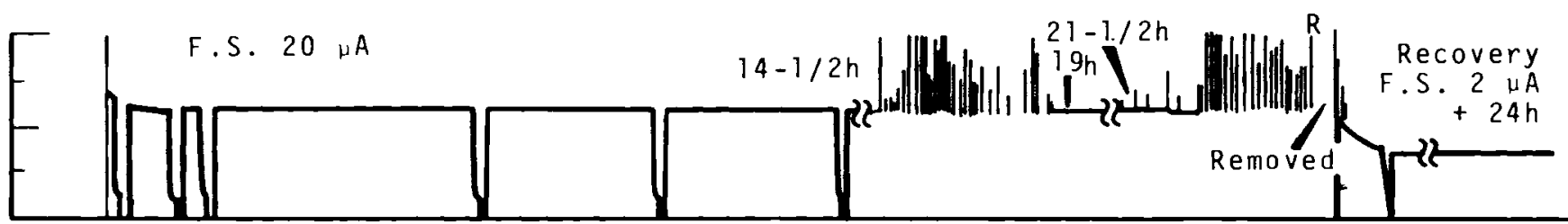

b) Experiment 6 , Passivated Diode Number 16 with Encapsulation

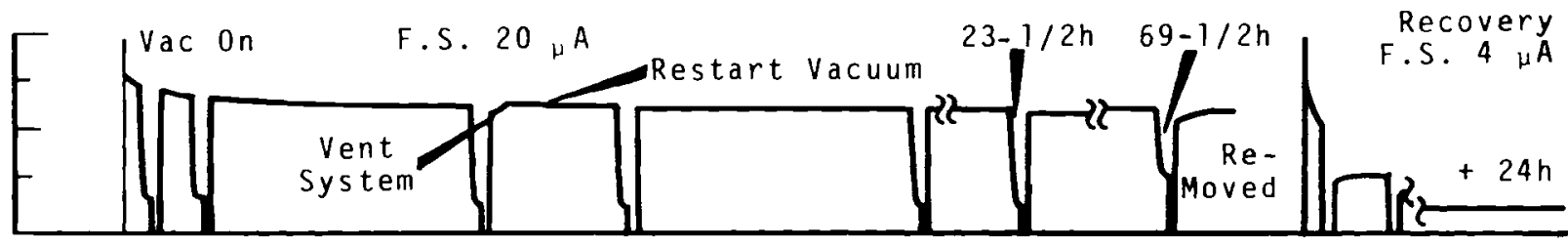

c) Experiment 8, Passivated Diode Number 18 In Vacuum Without Encapsulation

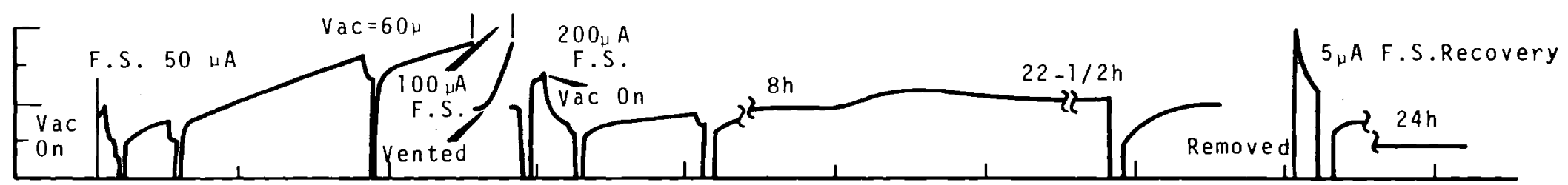

d) Experiment 9, Non-Passivated Diode Number 9 In Vacuum Without Encapsulation

FIGURE 9. Typical Reverse Current Recordings for VBias $=0.95 \mathrm{~V}_{\mathrm{BD}}$. (Scales are $1 \mathrm{hr} / \mathrm{in}$. for the horizontal and the vertical current scales are noted on each figure.) 
and passivated diodes, respectively, with the encapsulation left intact. Experiments 8 and $\vartheta$ used passivated and nonpassivated diodes, respectively, with the cans removed and with a vacuum applied to the system.

For some explanation of the curves, the excursions to zero current occur during plotting of a V-I curve. The current in most cases remained on the strip chart recorder while the voltage decreased. Following the V-I plot, however, the bias voltage was set before the current was switched back to the strip chart. The current plateau on the downward excursion appears a reasonably assumed value for the unity multiplication, low voltage current. The excursion from the plateau to zero current occurs very near zero volts and, in fact, the voltage must reverse polarity slightly to actually drive the current to zero. Although not shown on the curves, the diode temperature increased from 75 to $95^{\circ} \mathrm{F}$ over a period of $30 \mathrm{~min}$ and stabilized at the latter temperature. Although this increase must be considered in analyzing the results, temperature generation of electron-hole pairs will be at least an order of magnitude smaller than that for the gamma generation term and will not be observable in the reverse current during irradiation. However, the temperature will produce a change in tine avalancine voltage of the diodes, which have a positive temperature coefficient of $0.1 \% /{ }^{\circ} \mathrm{C}$. For a temperature increase of about $10^{\circ} \mathrm{C}$, an increase in breakdown voltage of about $1.1 \%$ or $2.2 \mathrm{~V}$ for the usual $200 \mathrm{~V}$ diode occurs.

Inspection of the characteristics in Figure 9 shows a current decrease in passivated diodes during the warmup. The cause of this decrease, true to some degree for all passivated units, is related to the increase in breakdown voltage which effectively reduces the multiplication factor and, therefore, the measured current ( $\left.M \times I_{R}\right)$. If the breakdown voltage increases by $1 \%$ with the bias voltage held constant, the $\mathrm{V}_{\mathrm{r}} / \mathrm{V}_{\mathrm{B}}$ term in the expression for the multiplication becomes 0.94 rather than the 0.95 value before the change in 
breakdown voltage. Using $\mathrm{n}=3$ as before, the multiplication factor becomes 5.9 , a reduction of $15.7 \%$ over the multiplication factor of 7 before the temperature increase. This reduction explains the accompanying current reduction with increasing temperature, an effect in opposition to that normally expected of the current during diode heating. Nonpassivated diodes demonstrate little of this effect because the current always begins to increase almost immediately after entry into the gamma field, thereby masking any such effect which might be present. This current increase in the nonpassivated diodes does not appear to be a function of temperature, since many hours of continued increase is much longer than the temperature increase period. The actual value of the multiplication factor, somewhat different than for the preceding example, will be discussed in more detail later in the report.

The next point of interest, observed in all of the experiments, centers on the very nearly constant current throughout each test for the passivated diodes (ignoring the microplasma noise), with the maximum current occurring at the instant of entry into the gamma field before the multiplication was reduced by the increase in temperature. This predictable operation, except for the high occurrence of noise and breakdown, demonstrates expected performance. The performance remained the same with the encapsulation removed both with and without vacuum, thus showing the success of the passivation treatment especially in comparison with the nonpassivated devices.

The nonpassivated diodes performed in an obviously inferior fashion, at least with respect to reverse current stability in the gamma field. The reverse current continued to increase throughout the experiments for those nonpassivated diodes with intact encapsulation. For nonpassivated units without encapsulation, the increase in current became quite pronounced and occurred at a higher rate, but saturated at a high constant value after some time in the field. In fact, both diodes reached a maximum current and then decreased slightly. One 
diode saturated at $100 \mathrm{\mu A}$ after peaking at about $114 \mathrm{\mu A}$ while the other saturated at $19 \mu \mathrm{A}$ after peaking at $22 \mu \mathrm{A}$. Operation of the nonpassivated diodes, while depending on application of vacuum, evidenced no consistent effect. On one diode, venting the system from a vacuum of $25 \mu \mathrm{m}$ caused the current to decrease initially and then to increase, while venting with the second diode produced immediate current increases of up to $100 \%$. This effect contrasts the performance of the passivated devices in which negligible changes occurred. Thus, performance of the nonpassivated diodes certainly indicates the importance of environment to diode operation and that surface effects, as determined in part by the environment, sometimes become the most significant and least predictable effects observed during irradiation. Ionization of the encapsulation gas (ultra-dry air) in the nonpassivated diodes appears to be an important mechanism for changes in diode characteristics during and after irradiation. As mentioned earlier, this effect resulted in the primary cause of the Telstar failure.

The principal unexpected effect of the irradiation experiments occurred clearly with the nonpassivated diodes. This effect, demonstrated generally in the first hour of irradiation with progressive increase, centered on the failure of the current to return immediately to its normal value following removal of the bias, or following reduction of the bias to zero volts (to establish a V-I plot). The current did return to the initial value with time constants varying from 2 to 30 min, usually in an exponential manner but sometimes with a linear component over a portion of the range. The extent of this effect varied among the diodes from a barely noticeable degree in the passivated devices to current changes of up to $60 \%$ in some of the nonpassivated diodes. The current, after reduction to zero volts bias, in essence became $60 \%$ less than before the bias voltage moved to zero. Significantly, creation of this effect required bias reduction all the way to zero. Lowering the bias to $5 \mathrm{~V}$ or raising it to breakdown had no 
effect on the current after return to the operating bias. However, opening the bias circuit produced the same effect as did lowering the voltage to zero volts. Figure 9 depicts this in the series of exponentially decreasing spikes on the recovery portion of the recording for Experiment 5 .

Figure 10 shows a series of consecutive V-I plots which also demonstrate the effect. These plots were made starting at the point shown and then decreasing the voltage to zero, increasing it to breakdown, and so on without pausing. The manner in which the current decreases each time the voltage returns to zero shows clearly. An even more important manifestation of this effect, observed only for the nonpassivated diodes, centers on the fact that, if the bias voltage remains on during and following removal of the diode from the gamma field, the current will not recover to its preirradiation value. Evidence of this characteristic is shown in the recovery portion of the recording for Experiment 5 . Specifically, following removal of the diode from the gamma facility, the current decreased to about $6 \mu \mathrm{A}$ after temperature stabilization. This performance compares to a preirradiation current at the same bias voltage of $0.2 \mu \mathrm{A}$. Following two reductions to zero bias in the next 15 min, the current dropped in steps to $3 \mathrm{uA}$. With the diode remaining biased for the next $2.5 \mathrm{hr}$, no change in current was observed. At this point, several more reductions to zero voltage changed the current to a new constant value of $2.3 \mu \mathrm{A}$. Upon return of bias to the diode following $15 \mathrm{~min}$ of operation in breakdown, the current remained at $2.3 \mu \mathrm{A}$. After $4.25 \mathrm{hr}$ following removal from the gamma field, the bias circuit was opened and closed 12 times at 2 min intervals. This operation succeeded in reducing the bias current to $1.5 \mu \mathrm{A}$. A repeat $30 \mathrm{~min}$ later resulted in a subsequent reduction to $1 \mu \mathrm{A}$. Removal of the bias for the next $12 \mathrm{hr}$ reduced the current to $0.4 \mu \mathrm{A}$, very nearly the preirradiation current. Thus, the conclusion from this test series shows that the bias voltage must be removed to effect recovery of the nonpassivated diode. This same type of recovery technique, used in 


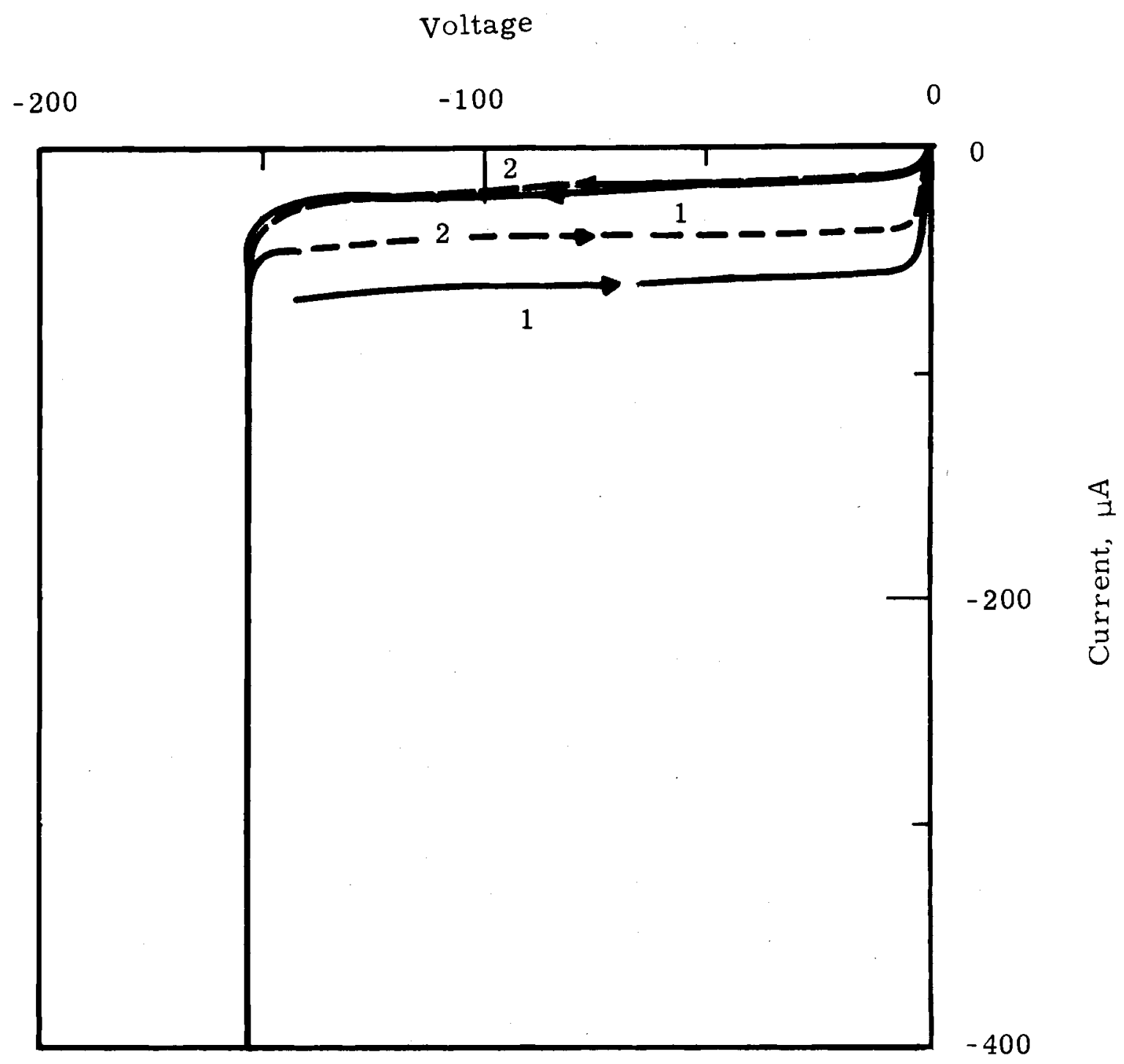

FIGURE 10. Consecutive V-I Plots Showing Effects of Dropping to Zero Bias Volts 
restoring to operation the failed semiconductors in the Telstar satellite, seems to point to a possible surface accumulation of charge on opposite sides of the junction where recombination can occur only after the field producing the charge separation and accumulation reduces to zero.

Figure 2 appears to be the most appropriate model of charge separation and accumulation due to surface field across the junction region. The $\mathrm{SiO}_{2}$ surface treatment appears to significantly reduce this effect, which proved to be very minor in the passivated diodes. Recovery occurs within $30 \mathrm{~min}$ after removal from the field and with the bias remaining on.

The only noticeable effect of irradiation on the passivated diodes appeared to be large amounts of microplasma breakdown with complete failure in two cases. One failure occurred after 50 min of irradiation, but the second occurred within 2 min after removal from the gamma field, although the diode had become noisy several times during the experiments. Both diodes remained ineffective the day after removal but, significantly, the one failing upon removal recovered after return to the gamma field and following a reduction in bias to zero volts to make a V-I plot. The achieved recovery restored its original preirradiation characteristics. Although possibly coincidental due to small sample, the noisy operation and failure occurred only for the canned devices. The uncanned diodes operating in a vacuum exhibited no noise other than that produced by an occasional single microplasma burst in the first few hours of the experiment. Observations made with the passivated diodes are difficult to explain, although the effects may relate to surface conditions. It may be important that 2 of the 10 passivated diodes exhibited this same type of microplasma noise without irradiation, thus indicating some initial instability in the diodes. These two diodes were not irradiated.

Table I illustrates the manner in which the multiplication factor, M, changed during the experiments. The method of calculation, however, may cast doubt on those values obtained after the first half hour. 
The multiplication factor results from dividing the bias current by the value at the plateau in the strip chart recording obtained as the voltage decreased towards zero. This method will be valid only if surface contributions remain small, a condition probably not fulfilled after some time in the gamma field. From the form of the multiplication equation, $M=\left(I-I_{S}\right) / I_{R}$, where $I$ is the current at the operating bias, $I_{S}$ the surface contribution, and $I_{R}$ the current at low bias voltages, significant surface contributions will clearly produce errors in calculations made with $I_{S}$ assumed to be negligible. This may very well be the reason for the apparent increase in multiplication factor for some of the experiments. Although, the irradiation may be responsible for the change in multiplication, the mechanism for this change is not known. As mentioned previously, a reduction in multiplication can be expected and predicted during the first $30 \mathrm{~min}$ due to the temperature-induced change in breakdown voltage.

TABLE I. Multiplication at Different Times During Experiments

\begin{tabular}{|c|c|c|c|c|c|}
\hline Experiment & Diode Type & Time of Entry & $1 / 2 \mathrm{hr}$ & $1 \mathrm{hr}=$ & Time of Removal \\
\hline 3 & Nonpassivated & 2.57 & 2.4 & 2.4 & 3.3 \\
\hline 4 & Passivated & 15.0 & 14.0 & 14.0 & 12.0 \\
\hline 5 & Nonpassivated & 3.0 & NA & 6.0 & 3.6 \\
\hline 6 & Passivated & 6.7 & 6.0 & 7.5 & 7.3 \\
\hline 7 & Nonpassivated & 1.4 & 3.0 & 3.0 & NA \\
\hline 8 & Passivated & 5.3 & 5.0 & 6.3 & 2.6 \\
\hline 9 & Nonpassivated & 1.7 & 1.2 & 1.15 & $\mathrm{NA}$ \\
\hline 10 & Passivated & 9.0 & 8.3 & NA & NA \\
\hline
\end{tabular}

Table II contains a listing of the important parameters measured during the experiments. Procedural errors during Experiment 1 and early diode breakdown in Experiment 2 prevented retrieval of valid data. Diode numbers greater than 10 indicate passivated devices, while 10 and below identify the nonpassivated units. All 
the diodes received about $4.5 \times 10^{7} \mathrm{R}$ of exposure except Diodes 4 and 8 which received $1.4 \times 10^{8} \mathrm{R}$. Comparison of the preirradiation current with that following entry to the ${ }^{60}$ Co field illustrates that the gamma generation component of the reverse current exceeds the preirradiation or temperature generated component by at least an order of magnitude. All passivated diodes exhibit nearly the same current during irradiation regardless of the variation in their thermally generated, preirradiation current. The measured value of the gamma generated current in the passivated units closely approaches the predicted value of $10.5 \mu \mathrm{A}$ given in Equation (15).

TABLE II. Important Parameter Measurements During Experiments

\begin{tabular}{|c|c|c|c|c|c|c|}
\hline Experiment & $\begin{array}{l}\text { Diode } \\
\text { ID No. }\end{array}$ & $\begin{array}{c}\text { Breakdown } \\
\text { Voltage }\end{array}$ & $\begin{array}{l}\text { Preirradiation } \\
\text { Bias Current, } \mathrm{A} A\end{array}$ & $\begin{array}{l}\text { Time of Entry } \\
\text { Irradiation } \\
\text { Current, } \mu \mathrm{A}\end{array}$ & $\begin{array}{c}\text { Final } \\
\text { Irradiation } \\
\text { Current, }, \mathrm{A} \\
\end{array}$ & $\begin{array}{c}\text { Final } \\
\text { Recovery } \\
\text { Current, } u \mathrm{~A} \\
\end{array}$ \\
\hline 3 & 4 & 210.0 & 0.95 & 8 & 9 & 0.9 \\
\hline 4 & 17 & 203.0 & 0.7 & 15 & 12 & $\begin{array}{c}0.75 \\
\text { Microplasma } \\
\text { Noise }\end{array}$ \\
\hline 5 & 10 & 212.8 & 0.2 & 12 & 40 & 0.4 \\
\hline 6 & 16 & 203.8 & 0.1 & 13.5 & $\begin{array}{l}11 \\
\text { Microplasma } \\
\text { Noise }\end{array}$ & 0.4 \\
\hline 7 & 8 & 202.0 & $\mathrm{NA}$ & 7.3 & 18 & 0.3 \\
\hline 8 & 18 & 203.0 & 0.2 & 16 & 13 & 0.4 \\
\hline 9 & 9 & 164.6 & 1.0 & 20 & 100 & 1.0 \\
\hline 10 & 19 & 204.4 & 4.0 & 15 & 13 & 0.3 \\
\hline
\end{tabular}

Figures 11 through 14 depict typical V-I curves obtained throughout Experiment 4 and show characteristics of the diode before, during, and after irradiation. The first curve taken during irradiation, Figure 12, illustrates a normal plot, but the second, Figure 13, shows the occurrence of premature breakdown. Few of the diodes evidenced this premature breakdown. For reference, Figure 10 showed the effects on the V-I plot of cycling a nonpassivated diode between zero volts and breakdown. 


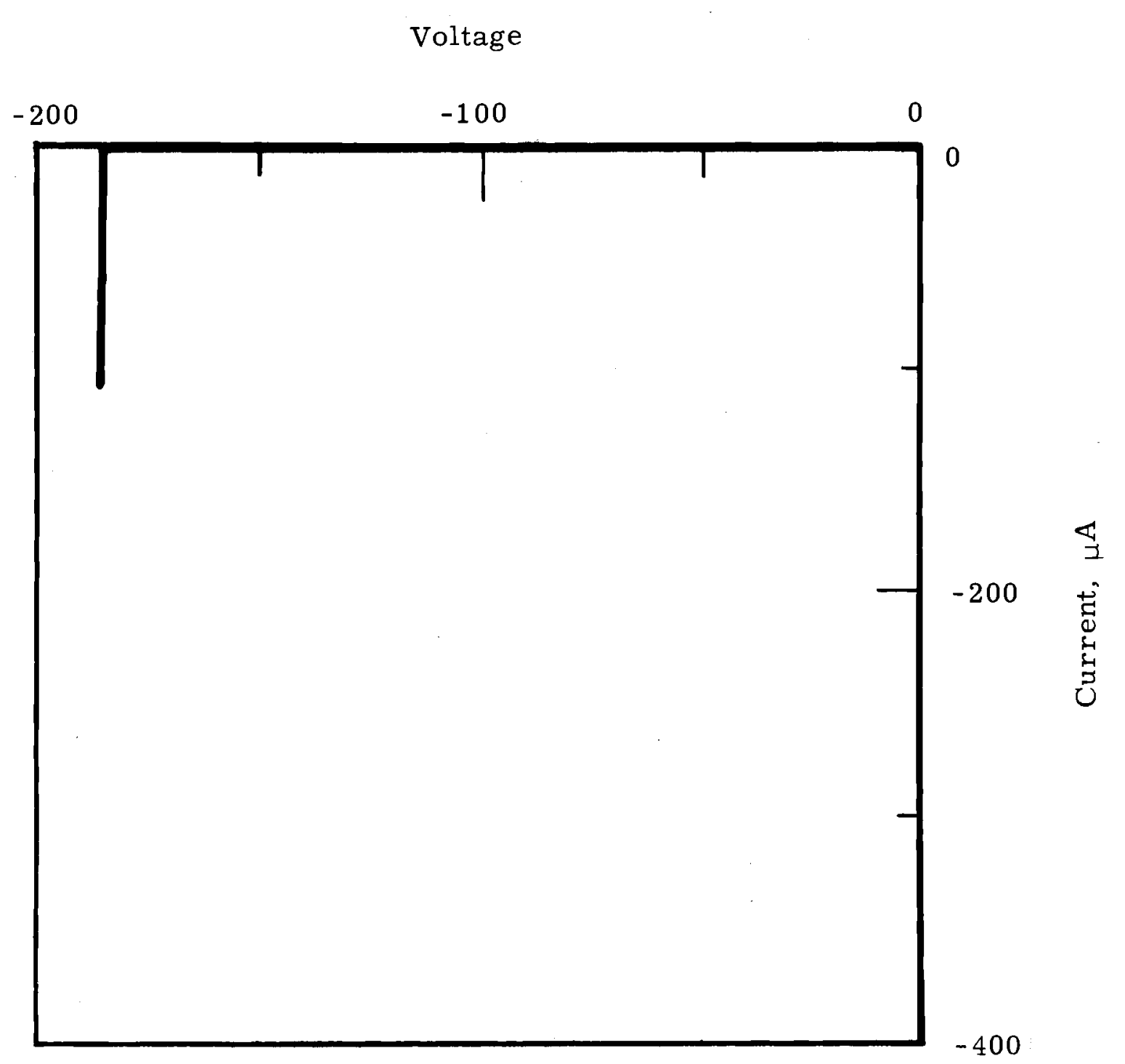

FIGURE 11. Preirradiation V-I Curve - Diode Number 17 
44

BNWL-788

Voltage

$-200$

$-100$

0

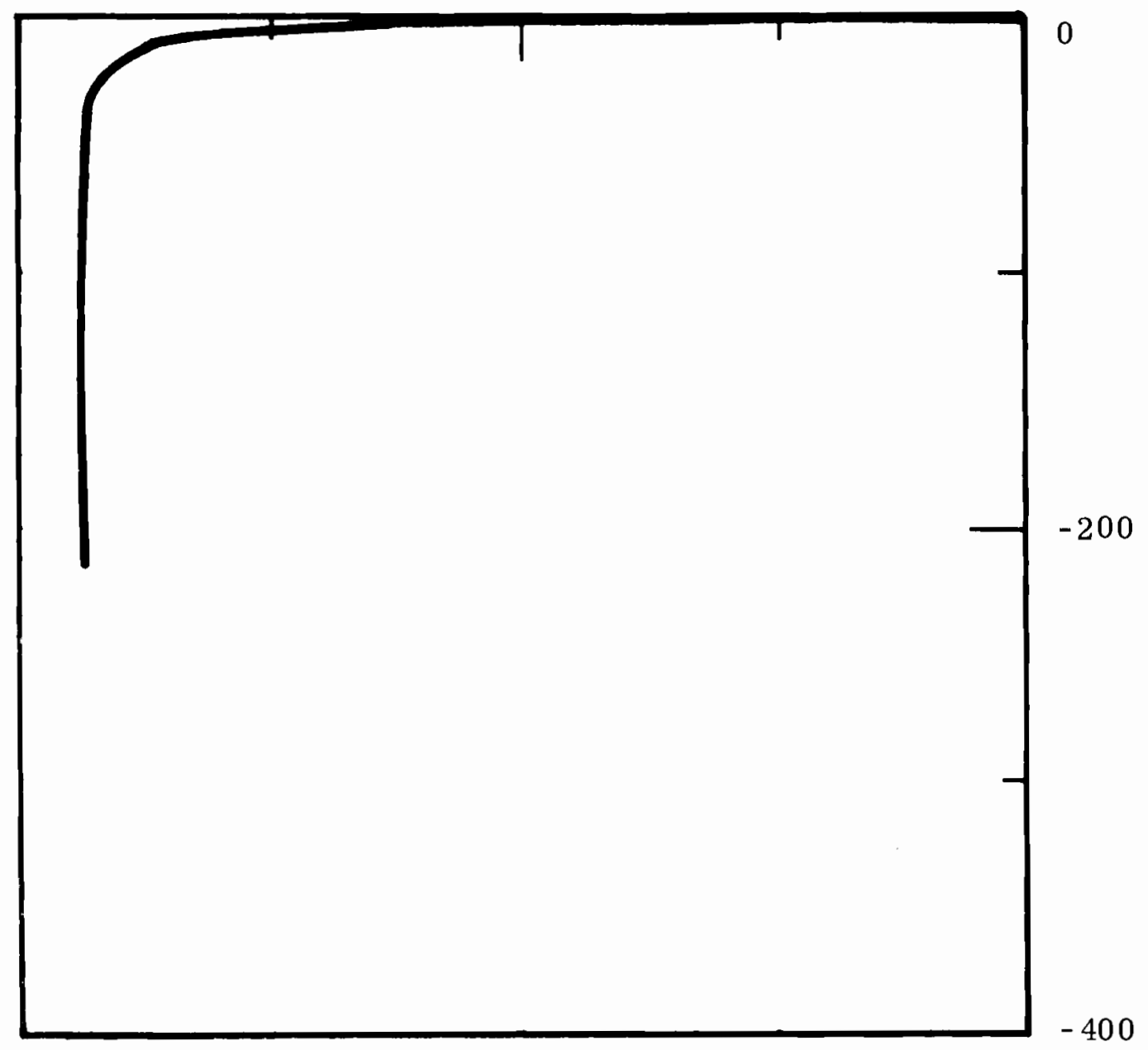

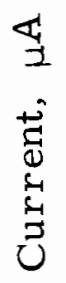

FIGURE 12. Normal Irradiation V-I Curve - Diode Number 17 


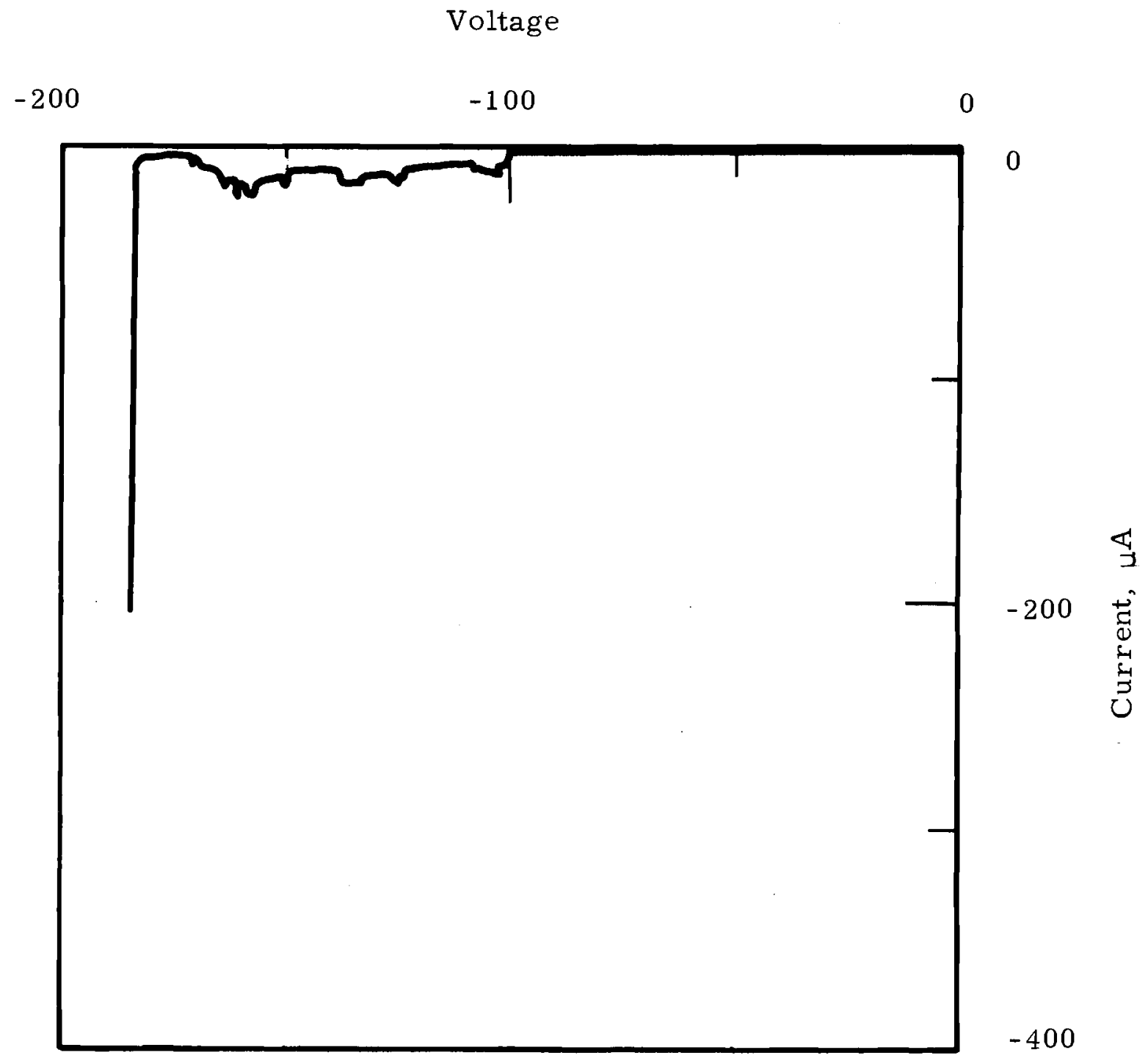

FIGURE 13. Premature Breakdown or Microplasma Diode Number 17 


\section{Voltage}

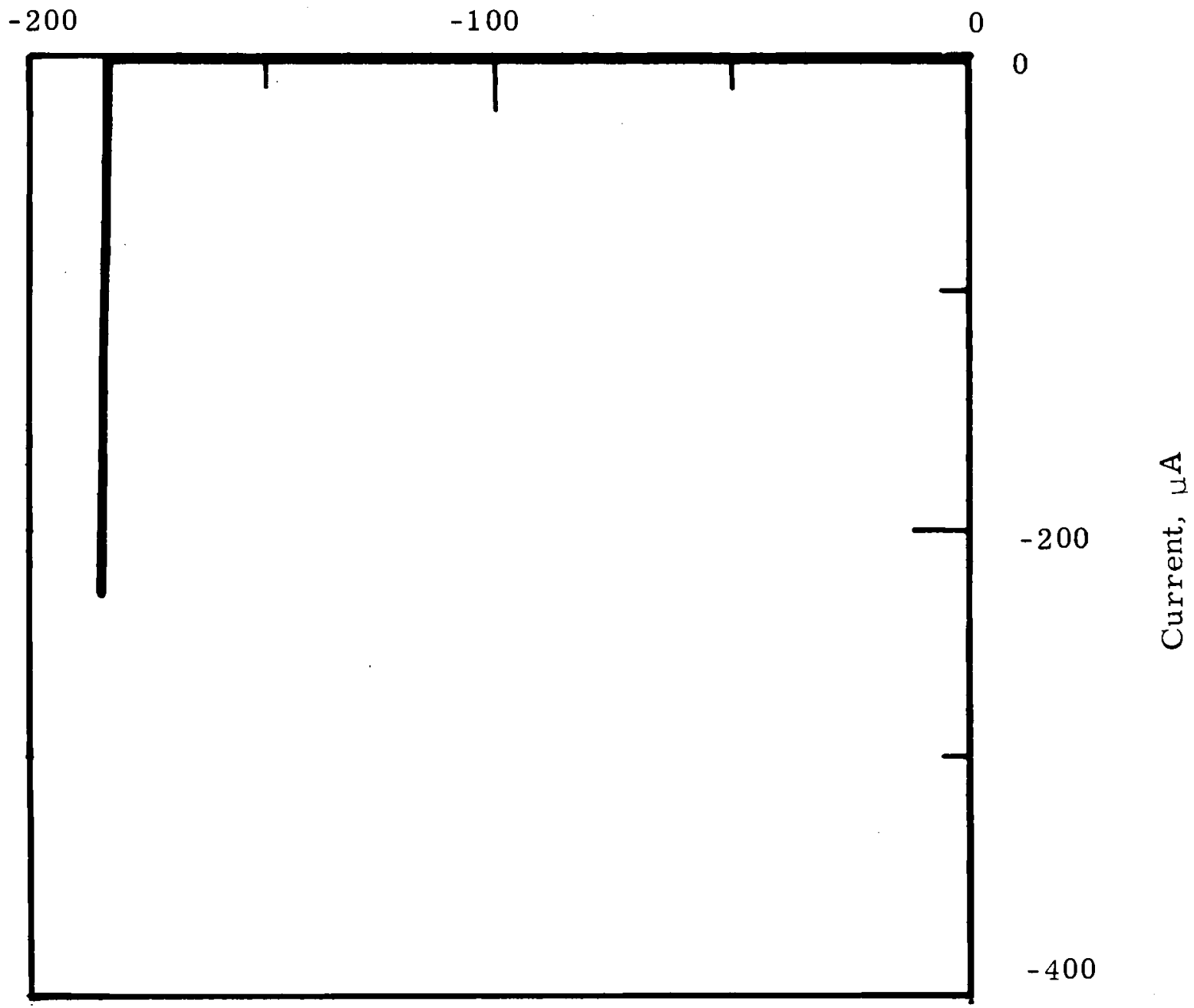

FIGURE 14. V-I Curve After Irradiation - Diode Number 17 


\section{CONCLUSIONS}

The ${ }^{60}$ Co irradiation experiments performed with the passivated and nonpassivated avalanche diodes operating at $5 \%$ below breakdown evidenced significant differences in irradiation effects, where total exposures up to $1.4 \times 10^{8} \mathrm{R}$ were obtained for both types of diodes. Except for the expected gamma generated current, the passivated diodes showed little or no change in characteristics, throughout the irradiation although failure rate was high. The nonpassivated diodes demonstrated much less predictable performance, especially in the continued current increase throughout the tests. However, no complete failures occurred.

The differences in the performance of the two types of diodes appeared to be due to surface effects of irradiation. The passivated diodes demonstrated immunity to changes in environmental conditions, while the nonpassivated units evidenced significant effects.

These experiments provided valuable basic information concerning the effects of irradiation, especially with respect to surface effects and to the advantages or disadvantages of passivation. However, a primary result of the investigations concerns the fact that particular passivated diodes can be used with success as radiation detectors for relatively high gamma levels, while the nonpassivated diodes evidence little value for such applications because of the rather large and unpredictable changes in measured current as a function of time in the gamma environment.

Another point of significance centers on the observed recovery characteristics of the two types of diodes. The nonpassivated diodes required reduction of the bias voltage to zero to effect recovery, while the passivated units recovered with the bias applied. Consideration of this situation may influence the application of diodes in critical circuits. 
The passivated diodes evidenced comparative insensitivity in unencapsulated form to environmental conditions, while the characteristics of the nonpassivated diodes were materially affected by the environment. Thus, for low-energy radiation detector applications where diode encapsulation may not be possible, the passivated units would be a logical choice.

Finally, the obtained experimental evidence points to irradiation surface effects as the cause for differences observed between the passivated and nonpassivated diodes. These effects remain difficult to predict with any degree of certainty, but $\mathrm{SiO}_{2}$ passivation as a surface treatment appears to be effective in reducing the problem to an acceptable level for many applications.

\section{ACKNOWLEDGEMENTS}

The author wishes to express his appreciation to Professor R. F. Knox of Washington State University and to W. G. Spear, N. S. Porter, L. D. Philipp, J. M. Frame, K. L. Swinth, and E. M. Sheen, all of Battelle-Northwest, for their helpful discussions and criticism concerning performance of the experiments and preparation of this report. 


\section{REFERENCES}

1. Burton V. Frank. Laboratory Experimental Analysis of Gamma Radiation Effects on Silicon Alloy Junction Semiconductor Diodes, AD-618-688. Picatinny Arsenal, Dover, New Jersey. 1965

2. C. G. B. Garrett and W. H. Brattain. "Some Experiments on, and a Theory of, Surface Breakdown, "J. Appl. Phys., vol. 27, no. 3, pp. 299-306. March 1956.

3. J. P. Mitchell and D. K. Wilson. "Surface Effects of Radiation on Semiconductor Devices, "The Bell System Technical Journal, pp. 1-79. January 1967.

4. E. H. Snow, A. S. Grove, and D. J. Fitzgerald. "Effects of Ionizing Radiation on Oxidized Silicon Surfaces and Planar Devices, " Proceedings of the IEEE, vol. 55, no. 7, pp. 1168-1185. July 1967.

5. A. R. Jones. Unpublished Data. (Personal communications)

6. G. C. Huth. "Recent Results Obtained with High Field Internally Amplifying Semiconductor Radiation Detectors," IEEE Transactions on Nuclear Science, NS-13. February 1966.

7. William Shockley. "Problems Related to $\mathrm{p}-\mathrm{n}$ Junctions in Silicon, "Solid-State Electron., vol. 2, no. 1, pp. 35-67. 1961.

8. J. L. Moll and R. Van Overstroeten. "Charge Multiplication in Silicon p-n Junctions," Solid State Electron., vol. 6, pp. 147157. 1963.

9. A. G. Chynoweth. "Ionization Rates for Electrons and Holes in Silicon, "Phys. Rev., vol. 109, no. 5, pp. 1537-1540. March 1958.

10. R. L. Batdorf, A. G. Chynoweth, G. C. Dacey, and P. W. Foy. "Uniform Silicon p-n Junctions. I. Broad Area Breakdown," J. Appl. Phys., vol. 31, no. 7, pp. 1153-1160. July 1960

11. A. R. Jones. "The Application of Solid State Amplifying Radiation Detectors in Health Physics, "presented at 1967 Health Physics Society Meeting held in Washington, D. C.

12. A. S. Grove. Physics and Technology of Semiconductor Devices. John Wiley \& Sons, Inc., New York, N. Y. 1967.

13. Andrew S. Grove, Otto Leistiko, Jr., and William W. Hooper. "Effect of Surface Fields on the Breakdown Voltage of Planar Silicon p-n Junctions, "IEEE Transactions on Electron Devices, vol. ED-14, no. 3, pp. 157-162. March 1967.

14. A. S. Grove and D. J. Fitzgerald. "The Origin of Channel Currents Associated with $\mathrm{p}^{+}$Regions in Silicon, "IEEE Transactions on Electron Devices, vol. ED-12, no. 12, pp. 619-626. December 1965. 
15. A. S. Grove and D. J. Fitzgerald. "Surface Effects on p-n Junctions: Characteristics of Surface Space-Charge Regions Under Non-Equilibrium Conditions, "Solid-State Electron., vol. 9, pp. 783-806. 1966.

16. J. L. Moll. Physics of Semiconductors. McGraw-Hill, Inc., New York, N.Y. 1964.

17. S. L. Miller. "Avalanche Breakdown in Germanium, "Phys. Rev., vol. 99, no. 4, pp. 1234-1235. August 15, 1955.

18. S. L. Miller. "Ionization Rates for Holes and Electrons in Silicon, "Phys. Rev., vol. 105, p. 1246. 1957.

19. M. M. Atalla, A. R. Bray and R. Lindner. Proceedings of the IEEE, 106, Part B Supplement, No. 17, pp. $\overline{1130-1137.1959 .}$

20. J. R. Mathews, W. A. Griffin and K. H. Olson. J. Electrochem. Soc., vol. 112, pp. 899-902. 1965.

21. M. Yamin. "Charge Storage Effects in Silicon Dioxide Films," IEEE Transactions on Electron Devices, vol. ED-12, pp. 88-96. March 1965. 
BNWL-788

APPENDIX 


\section{APPENDIX}

The following information on the tested diodes was provided by Motorola Inc.

On the nonpassivated diodes, the die is in the shape of a disc approximately $0.135 \mathrm{in}$. in diam by $0.010 \mathrm{in}$. thick. The " $n$ "type background concentration is roughly $10^{16}$ (phosphorus doped) and the "p" region is about $10^{18}$ (boron doped). The junction extends all the way across the die and is coated with a silicone varnish.

The passivated die, more complicated to describe, is $0.120 \mathrm{in.} \mathrm{square} \mathrm{by} 0.008 \mathrm{in}$. thick. The " $\mathrm{n}$ " type background concentration is about $5.5 \times 10^{15}$ and the "p" region has a gradient averaging $5 \times 10^{17}$. The junction does not extend all the way across the die but stops about 0.004 in. from the edge and comes to the anode surface. Covering of the junction surface with a thin layer of $\mathrm{SiO}_{2}$ accounts for the type of diode distinguished as "passivated".

The encapsulation gas for all of the diodes is ultra dry air. Enclosed also is a small disc of white paper made from fine glass fibers.

The author wishes to express his appreciation to Mr. James R. Schwin of Motorola Inc. for his cooperation in providing the above information. 


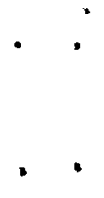




\section{DISTRIBUTION}

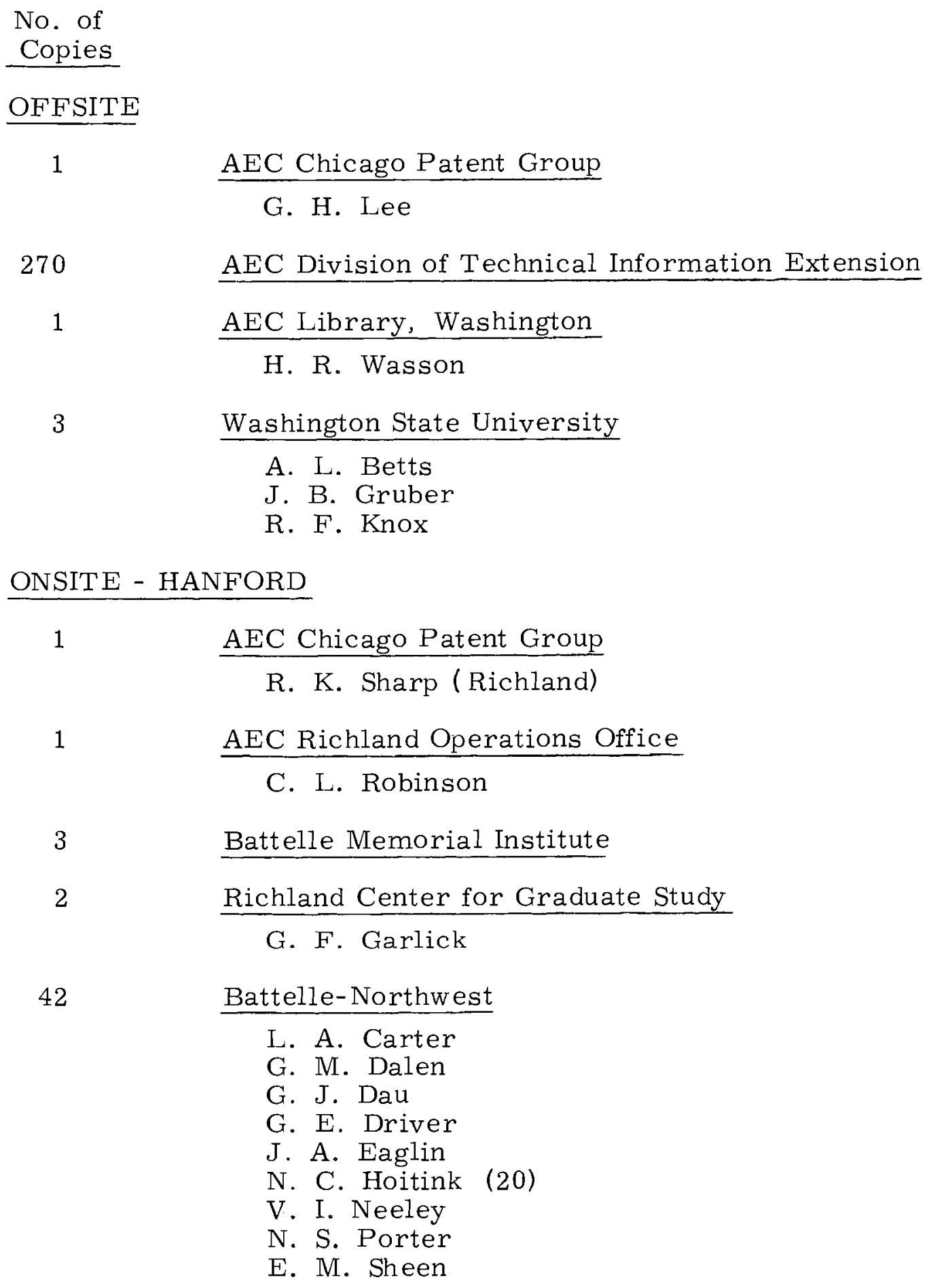

Battelle-Northwest

L. A. Carter

G. M. Dalen

G. J. Dau

G. E. Driver

J. A. Eaglin

N. C. Hoitink (20)

V. I. Neeley

N. S. Porter

E. M. Sheen 
Battelle-Northw est (contd)

J. C. Spanner

W. G. Spear (2)

J. L. Stringer

K. L. Swinth

D. C. Worlton

L. V. Zuerner

Technical Information File (5)

Technical Publications (2) 